University of Wollongong

Research Online

Australian Institute for Innovative Materials -

Papers

Australian Institute for Innovative Materials

$1-1-2019$

Two-dimensional transition metal dichalcogenides in supercapacitors and secondary batteries

\author{
Liangxu Lin \\ University of Wollongong, liangxu@uow.edu.au \\ Wen Lei \\ Wuhan University of Science and Technology \\ Shaowei Zhang \\ University of Exeter \\ Yuqing Liu \\ University of Wollongong, yuqing@uow.edu.au \\ Gordon G. Wallace \\ University of Wollongong, gwallace@uow.edu.au
}

See next page for additional authors

Follow this and additional works at: https://ro.uow.edu.au/aiimpapers

Part of the Engineering Commons, and the Physical Sciences and Mathematics Commons

Research Online is the open access institutional repository for the University of Wollongong. For further information contact the UOW Library: research-pubs@uow.edu.au 


\title{
Two-dimensional transition metal dichalcogenides in supercapacitors and secondary batteries
}

\author{
Abstract \\ Supercapacitors and secondary batteries are indispensable and widely used energy storage components \\ in modern electrical and electronic facilities/devices. However, they both suffer from different technical \\ weaknesses which need to be thoroughly addressed to satisfy the increasing demand for clean energy \\ technologies. For many years efforts to overcome these technical challenges have reached their practical \\ limits, but recent progress on two dimensional (2D) materials, such as thin transition metal \\ dichalcogenides (TMDs), has been considered more encouraging. Owing to their thin and flexible aspects, \\ large electrochemical active surface area (EASA), high surface tunability, rich coordination sites, and both \\ "Faradaic" and "Non-Faradaic" electrochemical behaviours, 2D TMDs play particular roles in improving \\ many aspects of energy storage devices. This concise review summarizes current challenges facing both \\ supercapacitors and secondary batteries, and discusses how 2D TMDs can be utilized to improve their \\ performance. Building on their thin and flexible features, we further discuss how the emerging flexible and \\ thin energy storage devices can benefit from the 2D TMDs, and make suggestions as to how these 2D \\ TMDs can be engineered for future energy storage applications. \\ Disciplines \\ Engineering | Physical Sciences and Mathematics

\section{Publication Details} \\ Lin, L., Lei, W., Zhang, S., Liu, Y., Wallace, G. \& Chen, J. (2019). Two-dimensional transition metal \\ dichalcogenides in supercapacitors and secondary batteries. Energy Storage Materials, 19 408-423.

\section{Authors} \\ Liangxu Lin, Wen Lei, Shaowei Zhang, Yuqing Liu, Gordon G. Wallace, and Jun Chen
}




\title{
Two-dimensional transition metal dichalcogenides in supercapacitors and secondary batteries
}

\author{
Liangxu Lin ${ }^{\mathrm{a}, \mathrm{b}}$, Wen Lei ${ }^{\mathrm{a}}$, Shaowei Zhang, ${ }^{\mathrm{c},}$, Yuqing Liu ${ }^{\mathrm{b}}$, Gordon G. Wallace ${ }^{\mathrm{b}}$, Jun Chen ${ }^{\mathrm{b},{ }^{*}}$ \\ ${ }^{a}$ The State Key Laboratory of Refractories and Metallurgy, and Institute of Advanced Materials and Nanotechnology, Wuhan Univer- \\ sity of Science and Technology, Wuhan 430081, China. \\ ${ }^{b}$ ARC Centre of Excellence for Electromaterials Science, Intelligent Polymer Research Institute, Australia Institute of Innovative \\ Materials (AIIM), Innovation Campus, University of Wollongong, Wollongong 2500, Australia. \\ ${ }^{c}$ College of Engineering, Mathematics and Physical Sciences, University of Exeter, Exeter EX 4 4QF, United Kingdom.
}




\section{Two-dimensional transition metal dichalcogenides in supercapacitors and secondary batteries}

\begin{abstract}
Supercapacitors and secondary batteries are indispensable and widely used energy storage components in modern electrical and electronic facilities/devices. However, they both suffer from different technical weaknesses which need to be thoroughly addressed to satisfy the increasing demand for clean energy technologies. For many years efforts to overcome these technical challenges have reached their practical limits, but recent progress on two dimensional (2D) materials, such as thin transition metal dichalcogenides (TMDs), has been considered more encouraging. Owing to their thin and flexible aspects, large electrochemical active surface area (EASA), high surface tunability, rich coordination sites, and both "Faradaic" and "Non-Faradaic" electrochemical behaviours, $2 \mathrm{D}$ TMDs play particular roles in improving many aspects of energy storage devices. This concise review summarizes current challenges facing both supercapacitors and secondary batteries, and discusses how $2 \mathrm{D}$ TMDs can be utilized to improve their performance. Building on their thin and flexible features, we further discuss how the emerging flexible and thin energy storage devices can benefit from the $2 \mathrm{D}$ TMDs, and make suggestions as to how these $2 \mathrm{D}$ TMDs can be engineered for future energy storage applications.
\end{abstract}

Keywords: 2D TMDs; Supercapacitor; Secondary battery; Fast charge transport; Short ion-diffusion distance

\section{Introduction}

The supercapacitor and the secondary battery are essential elements of modern energy storage technologies. They could be key contributors to combatting increasing global challenges on energy, environmental and climate change, by storing and delivering clean energies (e.g. wind power and solar energy) to supply electronic/electrical devices without greenhouse gases emissions $[1,2]$. In addition to their booming applications in electrical vehicles [3-8], these energy storage techniques are also commonly used in current portable, implantable and wearable electronic devices (e.g. mobile phones) [9-14]. However, modern vehicles and heavy duty power devices are still largely reliant on non-renewable fossil fuels due to the mismatched efficiency of these energy storage devices [1]. For example, the low power density (normally $<1 \mathrm{~kW} \mathrm{~kg}^{-1}$ ) of secondary batteries and the very low energy density $\left(\sim 1-10 \mathrm{Wh} \mathrm{kg}^{-1}\right)$ of supercapacitors make them unsuitable for heavy-duty devices and long-term operation, respectively $[2,15,16]$. The energy storage components in small electronic devices also need urgent developments to improve the power performance and to provide additional features such as low weight, thin structure and flexibility [17-19]. How to design and develop electrode materials to realize these anticipated features and efficiently store/deliver energy has become one of the main challenges in this field. Nevertheless, recent developments in materials science suggest that $2 \mathrm{D}$ TMDs such as $\mathrm{MoS}_{2}, \mathrm{MoSe}_{2}, \mathrm{WS}_{2}, \mathrm{TiS}_{2}$, $\mathrm{NbS}_{2}$ and $\mathrm{VS}_{2}$ have great potential to fill the gap between the existing performance and the modern requirements of energy storage devices [20-27]. This particular role is owing to their exceptional superiorities (e.g. reactive surfaces and rich coordination sites) over traditional electrode materials and other $2 \mathrm{D}$ materials (e.g. graphene).
It is well-known that TMDs are a category of materials generally having the chemical composition of $\mathrm{TMX}_{2}$ (TM: transition metal, $\mathrm{X}$ : chalcogen, including similar chalcogenides with more than one TM atom and corresponding $\mathrm{X}$ atoms). The majority of them are layered (layers weakly bonded to each other by van der Waals forces (e.g. the group 4-7 TMDs) and some are non-layered (e.g. from groups 9 and 10) [21]. Bulklayered TMDs have three polymorphs of $1 \mathrm{~T}, 2 \mathrm{H}$ and $3 \mathrm{R}$ (the number represents how many TM-X-TM units are in the unit cell). They could be either $1 \mathrm{~T}$ or $2 \mathrm{H}$ (e.g. group 5 TMDs), and favour the $1 \mathrm{~T}(e . g$. groups 4,7$)$ or $2 \mathrm{H}$ structures (e.g. group 6), having physical properties varied from each other, i.e. IT TMDs are normally metallic and highly conductive, and their $1 \mathrm{H} / 2 \mathrm{H}$ phases are usually semiconductors with poor electrical conductivity [28-30]. Compared with the bulk form, mono- or fewlayered 2D TMDs, obtained either through top-down exfoliation of bulk materials or bottom-up syntheses, have dramatically changed properties because of the charge carrier confinement only in two dimensions and relating changes of the electronic structure [31-38]. Charge transport between the electrode and the TMD monolayer is also directly improved by avoiding the inefficient electron hopping between layers [36]. The directly increased edge ratio and surface exposure make 2D TMDs highly tunable (e.g. chemical doping, Janus- and hetero-structures), providing physical/chemical versatility with different bandgap energies and carrier types ( $\mathrm{n}$ - or p-type) [3440]. The electrochemical reactions of $2 \mathrm{D}$ TMDs can be both surface "Faradaic" and "Non-Faradaic" processes, which are considerably quicker than the traditional reactions of conventional anode material (e.g. graphite and bulk TMDs). Together with the unique structural anisotropy, all these intrinsic properties endow $2 \mathrm{D}$ TMDs with promising mechanical, chemical, and electrical merits in fulfilling the need of emerging electrochemical technologies (e.g. thin flexible energy storage devices). Recent progress in this field also indicates that $2 \mathrm{D}$ TMDs could be particularly well-positioned if their various features distinguished from the bulk and other $2 \mathrm{D}$ materials are suitably explored.

This concise review summarizes the challenges on current supercapacitor and secondary battery technologies and discusses how $2 \mathrm{D}$ TMDs can be used to improve their performance. Building on the various merits (e.g. thin and flexible) of $2 \mathrm{D}$ TMDs, the fabrication and performance of some selected flexible energy storage devices are introduced and highlighted as examples. In this paper, the design and development of next generation $2 \mathrm{D}$ TMD based materials for future energy storage applications are also outlined.

\section{Supercapacitor \\ 2.1 Challenges}

Supercapacitors are electrochemical devices which store charges in electric double layers (also called the "Helmholtz layer", with a thickness $\sim 3 \AA$ ) formed through physisorption of electrolyte ions onto porous carbon electrodes (Fig. 1a, the "Non-Faradaic" processes: no charge transfer redox reaction involves in this process) [2, 41-43]. They can offer very high charge/discharge rates (not limited by the electrochemical 
charge transfer kinetics of batteries) and long lifetimes (e.g. over a million cycles), potentially satisfying the needs of highpower electronic devices and electric vehicles [1, 2, 41]. However, after many years' efforts [44-49], practical applications of supercapacitors are still largely limited by their unsuitably low energy densities which are far lower ( several $\mathrm{Wh} \mathrm{kg}^{-1}$, an order of magnitude lower) than those of secondary batteries (Fig. 1c). Many approaches have been proposed to improve their energy densities by activating carbon electrode materials and combining other materials via near-surface pseudo-capacitive redox reactions (a Faradaic process involving a charge transfer between the electrode and the active material, but not limited by the slow mass diffusion and bulk phase change process in traditional secondary batteries, Fig. 1b). For example, exotic materials such as transition metal oxide nanoparticles have been frequently used to add pseudo-capacitance [50-55], but their low electrical conductance (e.g. $10^{-5}-10^{-6} \mathrm{~S} \mathrm{~cm}^{-1}$ of $\mathrm{MnO}_{2}$ nanoparticles [47]) conversely reduced the power density of the device. Besides, in a common hybrid supercapacitor electrode, the pseudo-capacitive redox reaction only occurs on the top-most surface (using a limited part of the whole nanoparticle, Fig. 1b), meaning that most of the material is wasted, reducing energy capacity and increasing cost. Rapid charge transport between the nanoparticle and carbon material is also critical for fast energy delivery, but this rapid process requires intact contact of the material and is unlikely to be realized by conventional approaches, i.e. full packing of the particle by carbon materials without scarifying the ion transport channel.
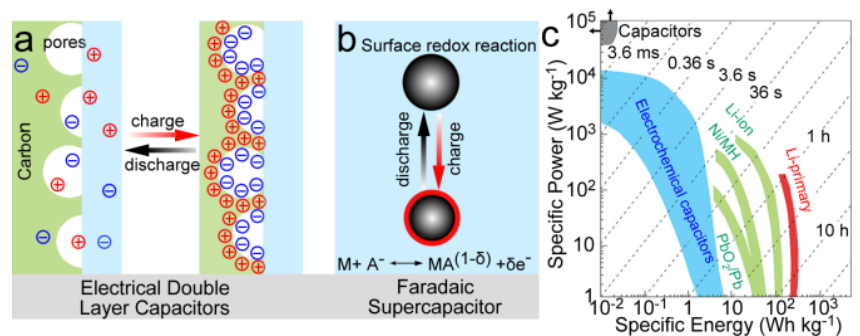

Fig. 1. (a-b) Schematic of the electric double layer capacitor (a) and the Faradaic supercapacitor (b). In Figure (b), the $M$ and $A^{-}$are the surface of the electroactive material and electron donating anion, respectively. $\delta \mathrm{e}^{-}$is the quantity of the electron which is related to the 'electrosorption valence'. The red circle represents the topmost surface of the particle processing the pseudo-capacitive redox reaction. (c) The Ragone plot shows specific power against specific energy. The time constant shown in the figure is the value of the energy density divided by the power. Figure (c) is reproduced from ref. [41] with permission. Copyright (2008) Springer Nature.

In electrochemical reactions, kinetics of electrode processes (e.g. adsorption/desorption kinetics and mass transfer) dominate the various performance of the energy storage device [47, 56 , 57]. A good supercapacitor electrode should feature high electrical conductivity and a large active surface area. Recently developed self-supporting and porous three dimensional graphene $(3 D-G)$ has the potential to offer improved electrode kinetics and mass transport with super short electron transport length and ion diffusion distance, which are key to improving the cycle life, energy capacity and power density of the energy storage device [56-58]. Unfortunately, the demonstrated energy capacities of modified and unmodified 3D-G (e.g. 5-40 Wh $\left.\mathrm{kg}^{-1}\right)$ [56, 59-69] are still far lower (1-2 orders) than that of modern Li-batteries [70, 71]. Improvements in the capacitance can be realized by adding exotic nanoparticles, but this addition would severely degenerate the power density and life time due to reasons described above. Improving the energy density and sustaining the various merits of supercapacitors (e.g. rapid charge/discharge rate and long life-time) have become the major challenges in this regard. Next, we discuss how $2 \mathrm{D}$ TMDs can be employed in supercapacitors to produce enhanced performance.

\section{$2.22 D$ TMDs in the supercapacitor}

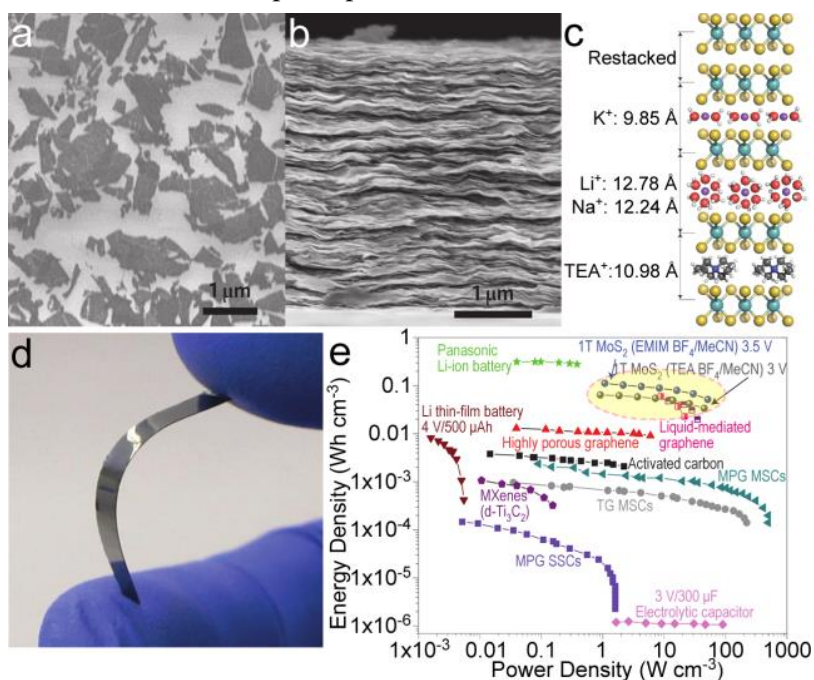

Fig. 2. (a-b) SEM images of the dispersed monolayered $1 \mathrm{~T}$ phase $\mathrm{MoS}_{2}$ nanosheets (a) and the cross-section of the stacked $\mathrm{IT} \mathrm{MoS}_{2}$ electrode. (c) Schematic shows the interlayer space of restacked $1 \mathrm{~T} \mathrm{MoS}$ nanosheets (set as $6.15 \AA$ ) before and after ions intercalation reaction. The $\mathrm{K}^{+}$and $\mathrm{Na}^{+} / \mathrm{Li}^{+}$ are coordinated with two and six water molecules, respectively. The intercalation of organic electrolyte $\left(\mathrm{TEA}^{+}\right)$gave an additional layer separation of $4.83 \AA$ Å. (d) Photograph of the $1 \mathrm{~T} \mathrm{MoS}_{2}$ sheets on flexible polyimide substrate. (e) Ragone plot of the volumetric power and energy densities of different materials. Figures are reproduced from ref. [37] with permission. Copyright (2015) Springer Nature.

Aside from the significantly improved edge ratio and surface exposure from their bulk phases, 2D TMDs also have graphene-like thin structures ( $1 \mathrm{~nm}$ thick, in the case of a monolayer) with ideal super short electron transport length and small ion transport distance for fast electrochemical processes. Investigations have suggested that $1 \mathrm{H} / 2 \mathrm{H}$ TMDs such as thin $\mathrm{MoS}_{2}$ sheets have comparable supercapacitor performance to that of carbon nanotube arrays and a theoretical capacity $\left(\sim 1000 \mathrm{~F} \mathrm{~g}^{-1}\right)$ greater than that of graphite $[72,73]$. Nevertheless, the development of $2 \mathrm{D}$ TMD-based supercapacitors has not been really successful due to the low electrical conductivity of most stable semiconducting $1 \mathrm{H} / 2 \mathrm{H}$ TMDs. By contrast, metallic IT TMDs are theoretically metastable and have the basal plane with more chemical activity over that of $1 \mathrm{H} / 2 \mathrm{H}$ phases $[21,74,75]$. They have very high electrical conductivity (e.g. 10$100 \mathrm{~S} \mathrm{~cm}^{-1}$ of monolayered $1 \mathrm{~T} \mathrm{MoS}_{2}$ sheet at room temperature, $10^{7}$ times more conductive than $1 \mathrm{H} \mathrm{MoS}_{2}$ monolayers) which is close to that of the best-performing reduced graphene oxide sheets $\left(\sim 100 \mathrm{~S} \mathrm{~cm}^{-1}\right)$ [37]. Recent progress has suggested that structures of some metallic 1T TMDs are actually stable in certain electrochemical processes [76-78], which promises the great future of $2 \mathrm{D}$ TMDs in supercapacitors. This promising application has been demonstrated by Chhowalla et al. in 2015, where monolayered $1 \mathrm{~T} \mathrm{MoS}_{2}$ sheets ( $70 \%$ phase ratio, Fig. 2a) were exfoliated from their bulk flakes using organolithium [37]. Owing to their high electrical conductivity, thin flexible supercapacitors can be fabricated purely from these $1 \mathrm{~T} \mathrm{MoS}_{2}$ sheets (stacking thickness up to $5 \mu \mathrm{m}$, Fig. 2b) without the addition of any binding agents or conductive additives (e.g. the film on polyimide substrate in Fig. 2d) [37]. The packed supercapacitor from this flexible electrode showed volumetric capacitances ranging from $400-700 \mathrm{~F} \mathrm{~cm}^{-3}$ in different aqueous electrolytes $\left(\mathrm{H}^{+}, \mathrm{Li}^{+}, \mathrm{Na}^{+}, \mathrm{K}^{+}\right.$), along with very high, stable (95\% capacity 
retention after 5000 cycles) energy and power densities in organic electrolytes (the shaded and highlighted region in Fig. 2e). Their cyclic voltammetry $(\mathrm{CV})$ curves in the used potential range (aqueous electrolyte and three electrodes: -1.o - o V vs open circuit potential (OCP); organic electrolyte and two electrodes: $3 \mathrm{~V}$ ) were all mainly capacitive featured [37], giving very high power and energy densities (Fig. 2e). The energy storage performance in organic electrolyte is significantly higher than those of MXenes (2D transition metal carbides, carbonitrides and nitrides), activated carbon, graphene materials and some thin Li-ion batteries (Fig. 2e). The efficient storage of organic electrolyte ions (e.g. the tetraethylammonium/TEA ${ }^{+}$) and the larger ions beyond the $\mathrm{Li}^{+}$(e.g. $\mathrm{Na}^{+}, \mathrm{K}^{+}$) was mainly owing to the dislocated layers in stacked sheets with both the interlayer space around 6.15 and 11.65-12.15 $\AA$ which highly matches the size of these ions (Fig. 2c). Following this principle, other $2 \mathrm{D}$ TMDs with high electrical conductivity (e.g. $1 \mathrm{~T} \mathrm{WS}$ and $1 \mathrm{~T} \mathrm{VS}_{2}$ sheets) and similar large interlayer spaces are also expected to be highly promising in building high-performing supercapacitors.

Besides these $1 \mathrm{~T}$ TMDs, recently developed ternary sulfides, the Ni-Co-S [79-82], could be more interesting in supercapacitors owing to their high stability, rich redox reaction sites (over that of the corresponding binary $\mathrm{Ni}$ or Co sulphides [79]) and outstanding electrical conductivity, i.e. the $\mathrm{NiCO}_{2} \mathrm{~S}_{4}$ has the electrical conductivity of around $10^{3}-10^{4} \mathrm{~S} \mathrm{~cm}^{-1}$ at room temperature [8o-81], which is 1-2 orders higher than that of $1 \mathrm{~T} \mathrm{MoS}_{2}$ monolayers (10-100 S cm${ }^{-1}$ ) [37]. Supercapacitors built from these ternary sulfides with traditional forms (e.g. nanofibers, ${ }_{3} \mathrm{D}$ structures) have been demonstrated by different groups [83-85]. Although the fabrication of ultrathin monolayered ternary sulfides is still challenging, a recent study on $\mathrm{CoNi}_{2} \mathrm{~S}_{4}$ nanosheets (thickness: around $20 \mathrm{~nm} ; 2 \mathrm{D}$ size: micrometers) based electrode has provided a high capacitance of $1117 \mathrm{~F} \mathrm{~g}^{-1}$ (at $2 \mathrm{~A} \mathrm{~g}^{-1}$, three electrodes technique, $6 \mathrm{M} \mathrm{KOH}$ ) and good rate performance (e.g. $1002 \mathrm{~F} \mathrm{~g}^{-1}$ at $10 \mathrm{~A} \mathrm{~g}^{-1}$ ) [86]. An asymmetric supercapacitor built from these ternary sulfides gave high power (e.g. $8 \mathrm{~kW} \mathrm{~kg}^{-1}$ at the energy density of $55.4 \mathrm{Wh} \mathrm{kg}^{-1}$ ) and excellent cycling performances ( $>80 \%$ capacity retained after 10000 cycles at $10 \mathrm{~A} \mathrm{~g}^{-1}$ ) [86]. Larger capacitance (2906 $\mathrm{F} \mathrm{g}^{-1}$ ) than the above demonstrated value of similar $\mathrm{CoNi}_{2} \mathrm{~S}_{4}$ sheets (thickness: around $45 \mathrm{~nm}$; 2D size: micrometers) based supercapacitor was also achieved at a current density of $5 \mathrm{~mA} \mathrm{~cm}$ [87]. These performances are already superior to that of their many counterparts with traditional forms $[86,87]$.

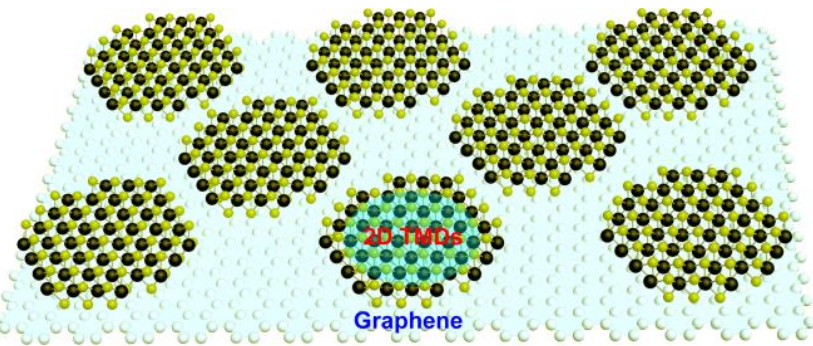

Fig. 3. Schematic shows the hybrid structure of $2 \mathrm{D}$ TMDs and graphene, where the $2 \mathrm{D}$ TMDs intimately contact the graphene's surface with their basal planes.

As for the thin $2 \mathrm{D}$ TMD materials with poor electrical conductivity (particularly the semiconducting $1 \mathrm{H} / 2 \mathrm{H}$ TMDs), hybrid structures from these TMDs and the graphene (Fig. 3, e.g. through physical stacking or chemical bonding) could be considered to potentially overcome many weaknesses of traditional hybrid supercapacitors, providing improved energy and power densities, long cycle life and improved safety. Unlike traditional nanoparticles (where only the topmost surface participates in the electrochemical process, Fig. 1b), the whole $2 \mathrm{D}$ TMDs (e.g. monolayers) and their highly active edges in this hybrid structure (Fig. 3) could contribute both the Faradaic and Non-Faradaic capacitance, improving material's usage and reducing cost. Comparing it with traditional secondary batteries, the near surface redox reaction is essentially different and associated with much higher energy delivery efficiencies (will be further highlighted in the next section together with an analysis of the secondary battery). In addition, $2 \mathrm{D}$ TMDs could intimately contact the graphene wall, which would ensure rapid charge transport between the electrode and the chemically active site (e.g. active sites on $\mathrm{1H}$ semiconducting TMDs) for high power density and improved rate performance. This structure is more promising when more electrically conducting TMDs nanocrystals (e.g. IT nanocrystals), chemical modifications and $3 \mathrm{D}-\mathrm{G}$ with large surface areas are introduced. Although hybrid electrodes from strictly monolayered $2 \mathrm{D}$ TMDs and graphene still need to be developed, recent reports on similar hybrid structures have confirmed that there is a flourishing future for $2 \mathrm{D}$ TMDs in supercapacitors [88-90]. For example, Ajayan and Ye et al. have demonstrated the hybrid electrode of $\mathrm{CoNi}_{2} \mathrm{~S}_{4}$-graphene-2D $\mathrm{MoSe}_{2}$ with graphene and thin $\mathrm{MoSe}_{2}$ sheets closely attached to each other, and highly conductive $\mathrm{CoNi}_{2} \mathrm{~S}_{4}$ nanoparticles on/between the layers [9o]. This electrode exhibited very high capacitance (1141 $\mathrm{F} \mathrm{g}^{-1}, 1 \mathrm{~A} \mathrm{~g}^{-1}$, three electrodes technique, all in $6 \mathrm{M} \mathrm{KOH}$ electrolyte), good rate $\left(961 \mathrm{~F} \mathrm{~g}^{-1}\right.$ at $5 \mathrm{~A} \mathrm{~g}^{-1}$ ) and cycling performances (108 \% capacitance retention after 2000 cycles, $20 \mathrm{~A} \mathrm{~g}^{-1}$ ). The supercapacitor assembled from this electrode also exhibited high power densities (e.g. $\sim 0.89$ and $13.3 \mathrm{KW} \mathrm{kg}^{-1}$ at energy densities of 38.6 and $23.7 \mathrm{Wh} \mathrm{kg}^{-1}$ ). The role of $2 \mathrm{D}$ TMDs in supercapacitors is further strengthened, particularly when the materials fabrication on various $2 \mathrm{D}$ nanocrystals has been proved to be increasingly successful [31-33, 91-96], which will be further introduced in the later section.

\section{Secondary Batteries}

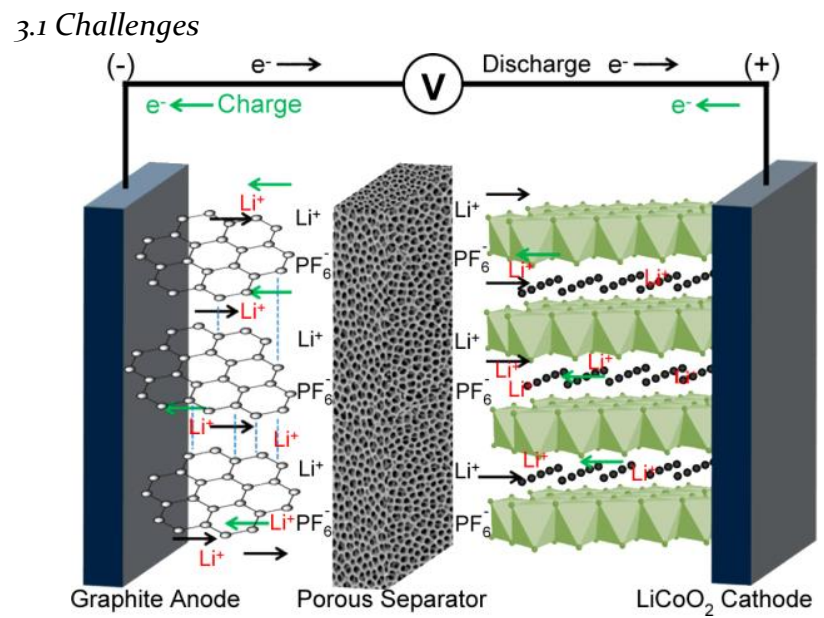

Fig. 4. (a) Schematic shows the first Li-ion battery. Reproduced from ref. [98] with permission. Copyright (2015) American Chemical Society.

Unlike supercapacitors, secondary batteries store and deliver energies through reversible chemical reactions (e.g. insertion reactions, alloying-dealloying reactions, phase transition reactions) at both electrodes $[97,98]$. The basic working mechanism of the secondary battery is presented in the schematic showing the first Li-ion battery (Fig. 4), which takes energy along with the ions' flow from the cathode to the anode, and 
reverses the process to release the energy [98, 99]. This pure Faradaic process endows much higher energy density of the secondary battery over that of the supercapacitor (Fig. 1c). Besides the charge transfer process, the energy storage/delivery of the traditional secondary battery is also limited by the slow ion diffusion and bulk phase change (e.g. the insertion/extraction and conversion reactions at electrodes in Fig. 4), giving much lower power densities than those of supercapacitors (Fig. 1c). Among various developed secondary batteries (e.g. lead acid, NiCd, NiMH and Li-ion batteries), the Li-ion battery is considered to be the most popular energy carrier in current electrical/electronic devices (e.g. mobile phones and laptops) [100-103], owing to advantages such as its relative high energy density, very low toxicity, high coulombic efficiency, larger working temperature range and maintenance-free features [99]. However, it still needs considerable improvement towards higher energy and power densities to meet the increasing demands from fields ranging from small portable electronic devices to long-range electric automobiles. Improvements in the energy density have been achieved by smart cell engineering, but better materials are still needed to further reduce the weight and volume of the device [98]. Unfortunately, improving the energy density via the modification (e.g. morphology, size, doping, band gap engineering) of traditional active materials has reached a level of maturity [99]. It has also reached a limit by increasing the operation voltage, due to the decomposition of most organic electrolytes $>5 \mathrm{~V}$.

In recent years, chemistries beyond the "Li-ion" have also been considered in building secondary batteries because of the increasing cost of $\mathrm{Li}$ resources [97]. These new energy storage routes include the use of other cheap charge carriers (e.g. $\mathrm{Na}, \mathrm{K}$, $\mathrm{Mg}$ and $\mathrm{Al}$ cations) and the implementation of conversion reactions (e.g. metal-air and Li-S batteries) [104-113]. However, compared with the Li-ion battery, the theoretical energy densities of batteries based on these new metal ions are normally low due to the larger ionic radius and heavier atomic mass than those of the $\mathrm{Li}^{+}$. The development of new electrode materials to allow the efficient insertion reaction of these larger ions is also highly sought after [97]. As for the conversion reaction route, batteries such as $\mathrm{Li} / \mathrm{O}_{2}, \mathrm{Li} / \mathrm{S}, \mathrm{Li} /$ metal halide, and $\mathrm{Li} /$ metal oxide exhibit many desired features such as lower equivalent weights and considerably higher energy densities (2-10 times greater than for current Li-ions batteries) [110-113] Nevertheless, achievement of these batteries with a long operation life is still difficult. Significant efforts in both the fundamental research and the manufacture are still needed to improve the performance of secondary batteries in many aspects (e.g. higher energy and power densities, lower cost, higher safety and longer life-time), which may include the development of novel electrode materials and new battery systems.

\section{$3.22 D$ TMDs in the secondary battery}

Although secondary batteries involve such technical challenges, recent developments suggest that their various performances can be potentially improved by combining 2D TMDs. Unlike graphite materials, TMDs have much larger interlayer spaces (e.g. $0.65 \mathrm{~nm}$ of $\mathrm{MoS}_{2}$ vs $0.33 \mathrm{~nm}$ of graphite) and related weaker van der Waals interactions between the layers. This interlayer space allows for energy storage with more sustainable larger ions (e.g. $\mathrm{Na}^{+}, \mathrm{K}^{+}$and $\mathrm{Mg}^{2+}$ ) if the electrical conductivity of the electrode can be well addressed for rapid charge transport. They also have suitable OCP values for the metal ion storage, i.e. many $2 \mathrm{D}$ TMDs have optimal OCP values between o-1 $\mathrm{V}\left(v s \mathrm{Na}^{+} / \mathrm{Na}\right)$ to maximize the energy density and prevent the formation of alkali metal dendrites [114].
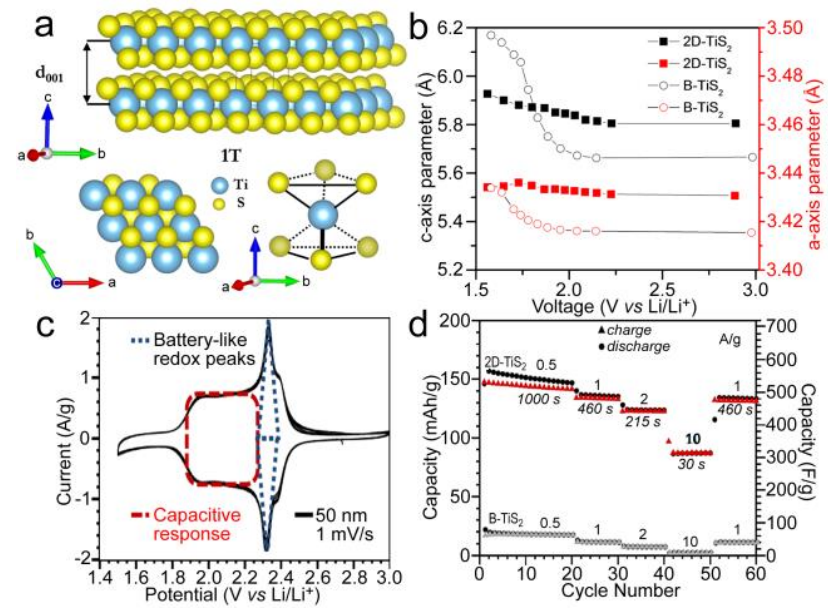

Fig. 5. (a) Schematic of the crystalline structure of $1 \mathrm{~T} \mathrm{TiS}_{2}$. (b) Comparison of the $a$ - and $c$-axis lattice parameters of different $\mathrm{TiS}_{2}$ materials against the potential during the intercalation reaction. (c) The CV curve of $2 \mathrm{D}-\mathrm{TiS}_{2}$ in a $\mathrm{Li}^{+}$electrolyte shows the composition of both the capacitive and the battery-like responses. (d) Rate capability of $2 \mathrm{D}-\mathrm{TiS}_{2}$ and $\mathrm{B}-\mathrm{TiS}_{2}$ films. Reproduced from ref. [115] with permission. Copyright (2015) American Chemical Society.

In secondary batteries, the advantage of $2 \mathrm{D}$ TMDs becomes more significant owing to the highly improved active surface ratios and rapid reactions of both surface adsorption/desorption and insertion/extraction (in multilayers) [115118]. Generally, the energy density of a secondary battery is determined by the reversible capacity and operating voltage; whilst the power density and rate performance are decided by the electronic/ion mobility in the electrode material. The previously mentioned near surface "Faradaic" capacitance of $2 \mathrm{D}$ TMDs can be fully exploited to develop high-performing secondary batteries. Unlike traditional secondary batteries, such surface reactions are much easier and faster by avoiding the slow insertion/extraction diffusion of the ions. Various reports have confirmed that $2 \mathrm{D}$ TMDs have significantly decreased ion diffusion barriers and increased adsorption energy from their bulk counterparts, resulting in larger energy and power densities, as well as better cycling performances [114-121]. The ion diffusion barriers of some $2 \mathrm{D}$ TMDs are actually already lower than that of the graphite anode $\left(\sim 0.2 \mathrm{eV}\right.$ for $\left.\mathrm{Li}^{+}\right)$[119], i.e. the $\mathrm{Na}^{+}$diffusion barriers on both the $1 \mathrm{H}$ and $1 \mathrm{~T} \mathrm{VS}_{2}$ monolayers are around 0.085 and $0.088 \mathrm{eV}$, respectively [122]. Such ion diffusion barriers can be further reduced upon suitable vacancy formation and surface doping, benefitting the energy storage processes in some small and smart self-powered devices, i.e. a solar light or thermal powered cell devices with very small voltages which cannot efficiently mount the energy carriers to the electrode for storage. In addition, many of these surface processes on $2 \mathrm{D}$ TMDs are also capable of providing high capacity (e.g. a $1914 \mathrm{mAh} \mathrm{g}^{-1}$ of $2 \mathrm{D} \mathrm{TiS}_{2}$ for $\mathrm{Ca} / \mathrm{Mg}$ storage and 1400 $\mathrm{mAh} \mathrm{g}^{-1}$ capacity of $2 \mathrm{D} \mathrm{VS}_{2}$ for Li storage $[116,120]$ ) and high operating voltage, giving much larger energy densities than that of graphene (e.g. 600-900 $\mathrm{mAh} \mathrm{g}^{-1}$ for Li storage) [116-121]. Both the energy and power densities can be further improved if we can fully exploit the multi-layered adsorption of ions and the interaction between the metal ions and the exposed TM atoms on the defected $2 \mathrm{D}$ TMDs [116]. Like the interstitial doping of 2D TMDs by $\mathrm{Ni}$ atoms (the formation of a metal-metal bond), the metal-metal interactions between the TM site (e.g. at the exposed edge and X-depleted site on the basal plane) and the 
smaller ions $\left(\mathrm{Li}^{+}, \mathrm{Na}^{+}, \mathrm{K}^{+}\right.$and $\left.\mathrm{Mg}^{2+}\right)$ are also highly possible [75].

In multilayered (e.g. bi- and tri-layered) $2 \mathrm{D}$ TMDs, rapid ion intercalation could also be realized, which is completely different from the slow ion insertion reaction in traditional bulk anode materials (the diffusion-controlled mechanism). This difference has been confirmed by demonstrating the rapid $\mathrm{Li}$ storage on thin (2-10 layers) $\mathrm{TiS}_{2}$ sheets with a lateral size of around $50-270 \mathrm{~nm}$ [115]. As suggested in Fig. 5a, the $2 \mathrm{D} \mathrm{TiS}_{2}$ nanosheets are 1T metallic materials with an interplanar spacing of $\sim 5.7 \AA$. $1 \mathrm{H} \mathrm{TiS}$, only appeared in the as-prepared nanocrystals. Compared with the bulk $\mathrm{TiS}_{2}$ material $\left(\mathrm{B}-\mathrm{TiS}_{2}\right),{ }_{2} \mathrm{D}$ $\mathrm{TiS}_{2}$ has a larger unit cell volume and smaller c-axis lattice expansion during the $\mathrm{Li}^{+}$insertion/extraction reaction (Fig. $5 \mathbf{b}$ ). More specifically, $c$-axis parameters of $2 \mathrm{D} \mathrm{TiS}_{2}$ and $\mathrm{B}-\mathrm{TiS}_{2}$ changed to 5.93 and $6.17 \AA$ respectively during the first cycle insertion reaction. Correspondingly, $2 \mathrm{D} \mathrm{TiS}_{2}$ nanosheets exhibited more stable structures and fewer volume expansions during $\mathrm{Li}^{+}$storage, which is more suitable for safer energy storage and longer life-time operation. Unlike conventional anode materials, the charge storage of $2 \mathrm{D}-\mathrm{TiS}_{2}$ also contained significant intercalation pseudo-capacitance (Fig. 5C), giving much higher energy and power densities (Fig. 5d). The formation of such pseudo-capacitance is also very fast with a quasi-2D process mechanism, and similar to the ion diffusion on the surface of monolayered TMDs (capacitive-controlled behaviour). Building on these features of $2 \mathrm{D}$ TMDs (even the multilayers), it can be expected that the pure or re-stacked monolayered $2 \mathrm{D}$ TMDs would provide high energy and power densities for the secondary battery, that are unlikely to be achieved with traditional structures and materials. The re-stacked 2D TMDs may also be more promising for the storage of ions with larger radius over that of $\mathrm{Li}^{+}$owing to the principally larger interlayer spaces. In this regard, however, efficient charge transport of the electrode (e.g. between the TMD layers) should be carefully addressed. The hybrid structure $\left(\mathrm{CoNi}_{2} \mathrm{~S}_{4}\right.$-graphene-2D MoSe [9o]) we introduced above was just in this position to realize the fast charge transport between the layers. In some $2 \mathrm{D}$ TMDs, charge transport between their stacked forms and cross-linked networks is already reported to be efficient for the Faradaic reaction (e.g. $1 \mathrm{~T} \mathrm{MoS}_{2}$ and ternary Ni-Co-S sulfide) [37, 123-124]. This has been demonstrated by Zhang et al. on the $3 \mathrm{D}$ network of $2 \mathrm{D} \mathrm{NiCO} \mathrm{S}_{4}$ nanosheets (thickness: $\sim 10 \mathrm{~nm}$, majority $2 \mathrm{D}$ size: 1-2 $\mu \mathrm{m}$ ) vertically aligned on carbon cloths. Building on the anode of this $3 \mathrm{D}$ network, a high reversible capacity of $\sim 1275$ $\mathrm{mAhg}^{-1}$ (at $1 \mathrm{~A} \mathrm{~g}^{-1}$ ), an acceptable good cycling performance $\left(\sim 1137 \mathrm{mAh} \mathrm{g}^{-1}\right.$ was retained after 100 cycles $)$ and rate performance (340 $\mathrm{mAh} \mathrm{g}^{-1}$ at $5 \mathrm{~A} \mathrm{~g}^{-1}$ and comparable to the theoretical capacity limit of carbon-based electrodes) of the assembled Li-ion battery were demonstrated [124]. Owing to the high electrical conductivity and rich surface chemistries (e.g. the $\mathrm{OH}^{-}$insertion/extraction reactions), ternary $\mathrm{Ni}-\mathrm{Co}-\mathrm{S}$ sulfide has also been investigated as the cathode for an aqueous rechargeable alkaline battery (anode: $\mathrm{TiO}_{2}$ ), although the energy density was not so high [125].

The rich surface chemistry and catalytic activity of $2 \mathrm{D}$ TMDs also make them promising for some conversion reactions (e.g. Li-S and metal-air batteries). It is know that the stabilization of the polysulfide shuttle process (the dissolution of intermediate lithium polysulfide) of the Li-S battery is mainly realized by confining the sulfur within the pores of various carbon materials. However, these strategies are still challenged by the low active material loading, poor adsorption of the polysulfides and the detachment of the lithium polysulfide [126-128]. A recent investigation suggested that the lithium polysulfide can be simply adsorbed by the edge of $2 \mathrm{D} \mathrm{WS}$ and $\mathrm{MoS}_{2}$ sheets owing to the unsaturated $\mathrm{S}$ atoms (Fig. 6, the middle structure) [128]. These edges also stabilized the polysulfide shuttle process during the conversion reaction of lithium polysulfides (Fig. 6, the middle and right structures) [128], showing many advantages over traditional Li-S batteries, i.e. the metallic edge of $2 \mathrm{D}$ TMDs (promises the fast charge-transfer kinetics), the higher electrocatalytic activity over that of carbon electrode, and the absence of physical encapsulation of polysulfides (favor for better rate performance) [128]. Higher loading of the lithium polysulfide is also reasonably expected upon appropriate surface chalcogen depletion which can be realized by various approaches $[31,129]$. In past few years, significant efforts have been made in developing the catalysis of $2 \mathrm{D}$ TMDs (e.g. the oxygen reduction/ORR and hydrogen evolution reactions/OER $[31,130])$. The catalysis at the edge and defected site of modified and unmodified 2D TMDs endows them with interesting futures in metal-air batteries [131-133]. For example, Asadi et al. have investigated both the OER and ORR at the edge of $1 \mathrm{~T}$ $\mathrm{MoS}_{2}$ nanosheets (thickness: majority 6-16 layers; 2D size: micrometers) in an ionic liquid, giving comparable catalytic activity to that of $\mathrm{Au}$ and $\mathrm{Pt}$ catalysts [132]. The $\mathrm{Li}^{-\mathrm{O}_{2}}$ battery demonstrated with this system performed capacity of 500 $\mathrm{mAh} \mathrm{g}^{-1}$ (at $0.1 \mathrm{~mA} \mathrm{~cm}^{-2}$ ) and good cycling performances (85\% capacity remained after 50 cycles). Nevertheless, significant improvements on the above $\mathrm{Li}-\mathrm{S}$ and metal- $\mathrm{O}_{2}$ batteries are still needed in future to approach their theoretical capacity with long life time.

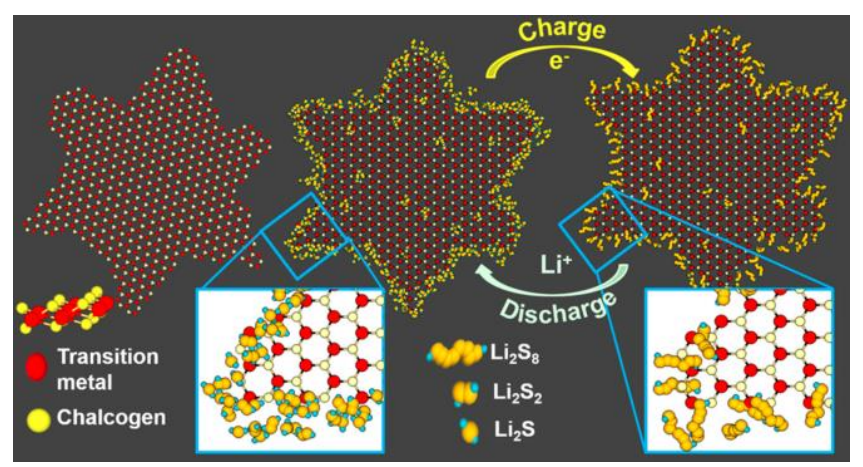

Fig. 6. Schematic of TMDs nanosheets for the Li-S battery, showing the conversions of lithium polysulfides during charge/charge process in a cathlyte solution. Reproduced from ref. [128] with permission. Copyright (2017) American Chemical Society.

\section{2D TMDs in flexible energy storage devices}

The roles described above of $2 \mathrm{D}$ TMDs in both the supercapacitor and the secondary battery applications have highlighted their promising futures in energy storage, particularly in the thin and flexible energy storage devices which can fully utilize the highly exposed active surface, and the thin and flexible aspects of $2 \mathrm{D}$ TMDs to meet diverse power needs of modern gadgets (e.g. health controls and wearable electronic devices) with anticipated features (e.g. low weight, safe, long cycle life, and high-speed operation) [134-138]. The means of integrating 2D TMDs into these flexible and thin energy storage devices will now be discussed with some selected examples.

In the Chhowalla's work mentioned above (Fig. 2), the flexible, thin supercapacitor fabricated from $1 \mathrm{~T} \mathrm{MoS}_{2}$ sheets (400$700 \mathrm{~F} \mathrm{~cm}^{-3}$ in aqueous electrolytes) showed very high stability and high energy and power densities (Fig. 2e) [37]. These performances were mainly determined by the reversible surface 
chemistry (e.g. ion adsorption and desorption), the high electrical conductivity and the large interlayer space of the restacked sheets, although they were also affected by the electrode fabrication techniques in most cases. Compared with their metallic phases, semiconducting TMDs such as $1 \mathrm{H} / 2 \mathrm{H}$ $\mathrm{MoS}_{2}$ are typically not as good at fabricating high-performing energy storage devices, mainly due to their low electrical conductivity. For example, Liu et al. have prepared $2 \mathrm{H} \mathrm{MoS}_{2}$ nanoflakes ( $2 \mathrm{D}$ size: 200 to $500 \mathrm{~nm}$, multilayered) via probe sonicating (note: the ratio of the thin sheets from this method is typically low, although many reports have claimed a high ratio of monolayers) [139]. They fabricated highly flexible electrodes by mixing these $\mathrm{MoS}_{2}$ nano-flakes with carbon nanotubes (CNTs) to improve the electrical conductivity and the mechanical strength [139]. Fig. 7a shows an image of such an electrode, which has the highest energy and power density of around 0.92 $\mathrm{mWh} \mathrm{cm}^{-3}$ and $2.1 \mathrm{~W} \mathrm{~cm}^{-3}$ (in polyvinyl alcohol/PVA- $\mathrm{H}_{2} \mathrm{SO}_{4}$ electrolyte, areal capacity of $37 \mathrm{mF} \mathrm{cm}^{-2}$ at the scan rate of 20 $\mathrm{mV} \mathrm{s}^{-1}$ ), respectively. These performances are significantly lower than those on pure $1 \mathrm{~T} \mathrm{MoS}_{2}$ thin sheets (Fig. 2e) [37] due to likely the lower electrical conductivity $[36,37]$, the thick sheet morphology (see their XRD pattern with an intense 002 diffraction peak of $\mathrm{MoS}_{2}$, although the average thickness of the flakes was claimed to be $2.5 \mathrm{~nm}$ ) [139], and the relatively lower chemical activity on the basal plane of the $1 \mathrm{H} / 2 \mathrm{H}$ sheet than that of their $1 \mathrm{~T}$ counterpart $[21,74,75]$.

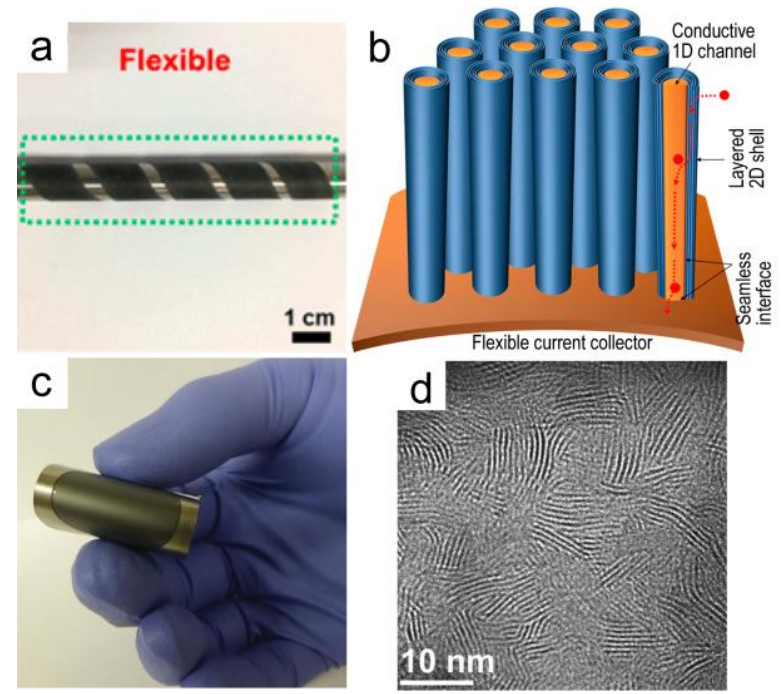

Fig. 7. (a) $\mathrm{MoS}_{2} / \mathrm{CNTs}$ coated paper shows excellent flexibility of the electrode. Reproduced from ref. [139] with permission. Copyright (2017) Elsevier. (b) Schematic of the hybrid core-shell structure of $\mathrm{WO}_{3}-\mathrm{WS}_{2}$ electrode. Reproduced from ref. [140] with permission. Copyright (2016) American Chemical Society. (c-d). The flexible electrode fabricated from the vertically aligned $\mathrm{MoS}_{2}$ sheets on the Mo foil (c) and the TEM image of the edge aligned sheets (d). Reproduced from ref. [146] with permission. Copyright (2014) John Wiley \& Sons.

For the most stable $1 \mathrm{H} / 2 \mathrm{H} 2 \mathrm{D}$ TMDs, high energy and power densities can actually be realized if the poor charge transport issue is adequately addressed. For example, Jung et al. proposed improving the charge transport between the electrode and the chemically active surface by forming a core-shell structure as shown as that in Fig. $\mathbf{7 b}$ [140]. In this hybrid structure, the $\mathrm{WO}_{3}$ core and $2 \mathrm{H} \mathrm{WS}$ shell ( $\sim 8-9$ layers) were intimately in contact with each other $\left(\mathrm{WO}_{3}\right.$ and $\mathrm{WS}_{2}$ were grown on the flexible $\mathrm{W}$ substrate with a general crystal growth model) to offer good mechanical robustness, which were also used for carrier transport and ionic absorption, respectively (Fig. $\mathbf{7 b}$ ). The flexible supercapacitor assembled from this electrode showed the highest energy and power densities of around 0.06 Wh $\mathrm{cm}^{-3}$ and $30 \mathrm{~W} \mathrm{~cm}^{-3}$ (areal capacity of $33 \mathrm{mF} \mathrm{cm}^{-2}$ at the scan rate of $10 \mathrm{mV} \mathrm{s}^{-1}$ ), respectively in $0.1 \mathrm{M} \mathrm{Na}_{2} \mathrm{SO}_{4}$ electrolyte [140]. The above performance was close to those found on pure 1T $\mathrm{MoS}_{2}$ sheets in an organic electrolyte [37] and greater than many MXenes and graphene based energy storage devices [140]. The power performances of the flexible device were highly stable even after being folded 100 times at $90^{\circ}$ and after 30,000 charge/discharge cycles. Like the pseudo-capacitance formed in metallic $\mathrm{TiS}_{2}$ sheets (the highlighted rectangular region in Fig. 5c), the achievement of this desirable power performance was also mainly because of the rapid ion adsorption/desorption on the surface and rapid intercalation in the interlayers of $2 \mathrm{D} \mathrm{WS}_{2}$ (the CV curve in the measured potential range was also capacitive featured) [140].

To improve the charge transport, the formation of vertically aligned semiconducting 2D TMDs on conducting and flexible substrates has also been considered. Like the vertically aligned 2D TMDs on electrically conducting substrates for improved electrocatalysis [141-145], these structures can offer more exposed active sites and sustain good electron transport between the electrode and the TMD's layer. The growth of such aligned $2 \mathrm{D}$ TMDs, in principle, is simple owing to the anisotropic feature of the crystal and the lowest surface energy at the basal plane. In the research by Tour et al. (in 2014), vertically aligned $\mathrm{MoS}_{2}$ sheets (around 5 layers, $2 \mathrm{D}$ edge size around $10 \mathrm{~nm}$, Fig. $\mathbf{7 c}$-d) were grown on the flexible Mo substrate with a general chemical vapor deposition (CVD) approach [146]. The flexible electrode (Fig. $\mathbf{7 C}$ ) was further packed as a supercapacitor and a high areal capacity was demonstrated around $12.5 \mathrm{mF} \mathrm{cm}^{-2}$ at the scan rate of $50 \mathrm{mV} \mathrm{s}^{-1}$ (in PVA and $1 \mathrm{M} \mathrm{LiOH}$ electrolyte) [146]. This capacity was further increased even after 10000 cycles, possibly owing to the formation of more activated sites [146]. Comparison of the areal capacity with other devices is difficult since it is highly dependent on the mass of the active materials in the electrode, the electrolyte and the scan rate. Nevertheless, these studies have demonstrated the mechanical robustness, the versatile surface and edge chemistry of $2 \mathrm{D}$ TMDs for promising flexible supercapacitors.

Besides the thin and flexible supercapacitor, 2D TMDs can also be engineered to build thin/flexible batteries which are more suited for storing larger ions beyond $\mathrm{Li}^{+}$(e.g. $\mathrm{Na}^{+}$and $\mathrm{K}^{+}$) owing to the large interlayer space. For example, considering the volume change of traditional materials during $\mathrm{Na}$ insertion (up to $500 \%$ in some cases), Singh et al. (in 2014) proposed a $\mathrm{Na}$ ion battery building on a hybrid composite of the thermally reduced graphene oxide (rGO) and $\mathrm{MoS}_{2}$ flakes [147], which has two predicted charge steps (intercalation and conversion reactions) as shown in the schematic (Fig. 8a). To prepare such composite paper, they mixed the pre-prepared GO and exfoliated $\mathrm{MoS}_{2}$ sheets, followed by a filtration treatment. Electrode materials were prepared via annealing the filtered paper at different temperatures in an argon atmosphere. As suggested by Fig. 8b-d, the annealed paper contained many sheets which were identified as the $\mathrm{MoS}_{2}$ and rGO sheets. Having made these preparations, Singh et al. demonstrated a charge capacity of $338 \mathrm{mAh} \mathrm{g}^{-1}$ (at current density of $25 \mathrm{~mA} \mathrm{~g}^{-1}$ ) at the first cycle with $83 \%$ capacity retention (approximately $98 \%$ average efficiency) during the 20 cycles test. Although these performances were not good enough and need significant improvements, the fabricated electrodes can be highly flexible depending on the addition ratio of $\mathrm{MoS}_{2}$ (Fig. 8e). Increasing the loading ratio of $\mathrm{MoS}_{2}$ improved the cell capacity but re- 
duced the flexibility. The demonstrated $6 \mathrm{oMoS}_{2}(60 \%$ mass ratio of $\mathrm{MoS}_{2}$ ) electrode had high fracture strength at $\sim 2.1 \mathrm{MPa}$ and modulus at $\sim 20 \mathrm{MPa}$ and a strain to failure at around $2 \%$. The energy storage and the mechanical performances can be further improved by modified fabrication approaches, as agreed by the authors. Nevertheless, this work has already demonstrated that $2 \mathrm{D}$ TMDs such as $\mathrm{MoS}_{2}$ can be successfully used in a flexible secondary battery beyond $\mathrm{Li}^{+}$.

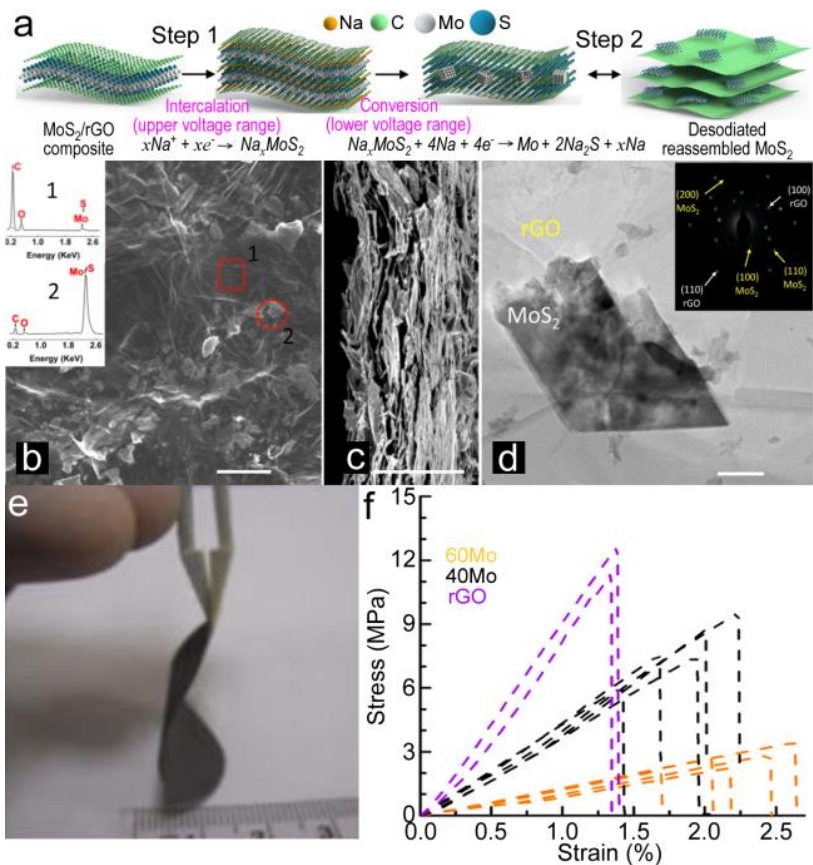

Fig. 8. (a) Schematic of the predicted $\mathrm{Na}^{+}$storage process of the $\mathrm{MoS}_{2} / \mathrm{rGO}$ composite. (b-c) SEM images of the $6 \mathrm{oMoS}_{2}$ composite paper. Insets in image (b) are the corresponding energy dispersive X-ray spectroscopy (EDS) spectra. (d) TEM image of the $6 \mathrm{OMoS}_{2}$ composite paper showing the hybrid structure of $\mathrm{MoS}_{2}$ and rGO. Inset is the SAED pattern of the hybrid flakes, giving different patterns from both the $\mathrm{MoS}_{2}$ and rGO and their dislocated structures in the composite. (e) Photo of a fabricated hybrid electrode. (f) The stress-strain plot for $\mathrm{rGO}, 4 \mathrm{oMoS}_{2}$, and $6 \mathrm{oMoS}_{2}$ free-standing papers Figures are reproduced from ref. [147] with permission. Copyright (2014) American Chemical Society.

In 2016, Li and Coleman et al. reported an improved method for building the flexible electrode and demonstrated better performances for Na storage [148]. This thin and flexible electrode (Fig. 9a) was manufactured from the liquid phase exfoliated $\mathrm{MoS}_{2}$ nanosheets and single wall CNTs. The flexibility and the stretchability of the electrode were made possible by the CNTs and $2 \mathrm{D} \mathrm{MoS}_{2}$ sheets and their networks (Fig. 9b-c). This film has a thickness of around 15-90 $\mu \mathrm{m}$ and electrical conductivity of up to $10^{2} \mathrm{~S} \mathrm{~cm}^{-1}$, although the CNT content was only 20 wt $\%$. Building on this fabrication, Li et al. demonstrated a specific capacity of $>400 \mathrm{mAh} \mathrm{g}^{-1}$, a volumetric capacity of $\sim 650$ $\mathrm{mAh} \mathrm{cm}^{-3}$, an areal capacity of up to $>6.0 \mathrm{mAh} \mathrm{cm}^{-2}$ with good cycling performance (tested for 100 cycles and a retention rate of up to $90 \%$, depending on the electrode thickness). Such energy storage performances are better than those of many other materials such as the commercial Li ion battery electrodes, the Si-based materials and the modified MXenes [149151]. Similar thin and flexible paper-like electrodes based on other $2 \mathrm{D}$ TMDs have also been reported. Fig. 9c shows a flexible electrode fabricated from the $2 \mathrm{D} \mathrm{SnS}_{2}$ and graphene nanoribbons. Like the case in the network of CNTs and $2 \mathrm{D} \mathrm{MoS}$ (Fig. 9b-c), the microstructure of this paper was also crossed with networks, giving flexibility of the electrode. The battery fabricated from this electrode had a high volumetric capacity of 508-244 mAh cm $\mathrm{m}^{-3}$ (current density from 0.1-10 $\mathrm{A} \mathrm{g}^{-1}$ ) and good capacity retention with 1500 cycles for $\mathrm{Na}^{+}$storage [152]. All these applications have demonstrated the highly effective roles of $2 \mathrm{D}$ TMDs in thin and flexible secondary batteries. Nevertheless, if these devices are to have more of the features anticipated in the future (e.g. high safety, implantable, smaller), additional research will be needed beyond the $2 \mathrm{D}$ materials, which may include cell fabrication techniques (e.g. the microfabrication technique), new electrolytes (e.g. solid-state or geltype electrolytes) and rational electrode design (e.g. the use of planar configuration and $3 \mathrm{D}$ electrodes).

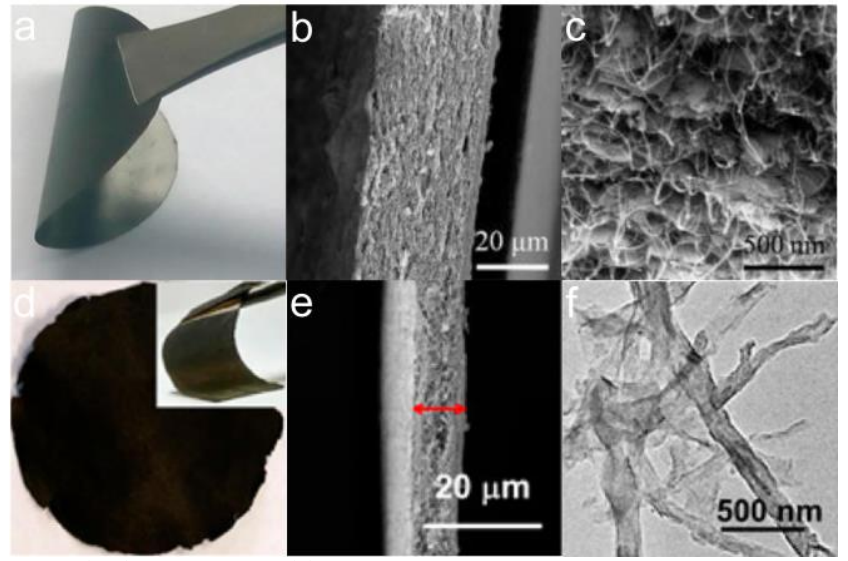

Fig. 9. (a-c) Photograph (a) and SEM microstructures of the flexible electrode (b-c) built by $2 \mathrm{D} \mathrm{MoS}_{2}$ and CNTs. Figures are reproduced from ref. [148] with permission. Copyright (2016) American Chemical Society. (d-f) Photograph (d) and SEM microstructures of the flexible electrode (e-f) built by $2 \mathrm{D} \mathrm{SnS} \mathrm{S}_{2}$ and graphene nanoribbons. Figures are reproduced from ref. [152] with permission. Copyright (2017) American Chemical Society.

\section{Fabrication of $2 \mathrm{D}$ TMDs}

Now, we summarize the main fabrication techniques (by categories) developed so far of the $2 \mathrm{D}$ TMDs associated with their applications in energy storage devices. Early studies of TMDs on catalysis, electronic and energy storage devices were mainly impeded by the lack of suitable fabrication approaches. The discovery of graphene in 2004 has triggered research interests in $2 \mathrm{D}$ TMDs materials, including their fabrication, properties and applications [153]. 2D TMDs can be achieved from their bulk flakes by using mechanical exfoliation (peel off the sheets layer by layer, a top-down approach) [38] like that of graphene [153], which is definitely unsuitable for large-scale implementations. Alternatively CVD (as well as the epitaxial growth) is one of the most frequently used techniques to achieving $2 \mathrm{D}$ TMDs with high quality (e.g. from monolayer to 2-5 layers) [154, 155]. It has been explored to grow vertically aligned TMDs sheets [140, 144-146], Janus [156], van der Waals heterostructures [157-159] and other complex vertically aligned heterostructures (with tuned charge transport and catalytic activity) [160] for both catalysis and energy storage applications. Nevertheless, these fabrications are still difficult for large scale preparation of materials using in energy storage devices. Comparing with the CVD technique, the solvothermal synthesis (and other similar bottom-up approaches in solution) is relatively cheaper. Directly bonding of $2 \mathrm{D}$ TMDs to the graphene can be realized via similar approach (in-situ growth in solvent) [161]. It is also suited for the growth of vertically aligned TMDs nanosheets with different sizes, enlarged interlayers and dopants $[142,143]$, but more works on reducing the thickness and size (the TMDs are still large and not thin enough) and building complex heterostructures for various purposes are need to be involved in future. 
Table 1. Electrochemical performances of various TMDs in the supercapacitor and the secondary battery. SCE: saturated calomel electrode; EMIMBF 4 : 1-ethyl3-methylimidazolium tetrafluoroborate; MeCN: methyl cyanide; TFSI: bis(trifluoromethylsulfonyl)imide; DOL: 1,3-dioxalane; DME: dimethyl ether; DEC: diethyl carbonate; EC: ethylene carbonate; EMC: ethyl methyl carbonate; DMC: dimethyl carbonate; SWCNT: single walled carbon nanotube; PVC: polyvinyl chloride.

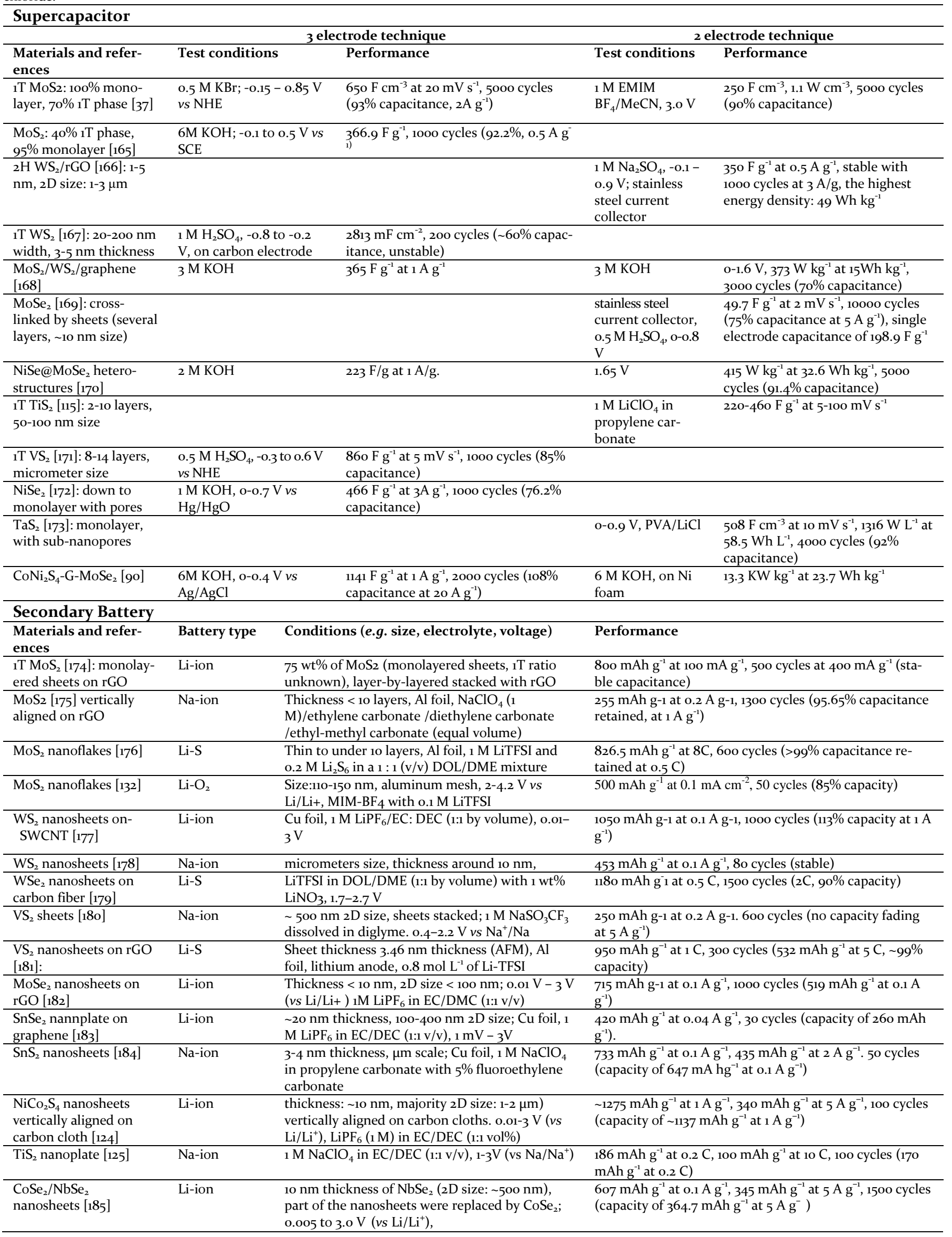


Besides the above bottom-up approaches, several top-down techniques have also been developed for $2 \mathrm{D}$ TMDs. We have witnessed that several energy storage devices were fabricated from the $2 \mathrm{D}$ TMDs based on liquid phase exfoliation (a surface energy related technique) and their modified approaches (e.g. acid-assisted approach) [139, 147, 162]. This technique can produce some monolayered TMDs [162], but is still unsuitable for large production due to the low yield of the ultrathin (e.g. 1-2 layers) TMDs sheets. This weakness also resulted in unsatisfied performances of the fabricated energy storage devices [139, 147]. By contrast, chemical exfoliation is considered more promising in generating monolayered TMDs with high yield [163-164]. It has also been developed for monolayered 1T TMDs nanocrystals and rich edge structures [91]. The only limitation of this approach is the use of unsafe chemicals (e.g. butyl lithium). More convenient techniques for monolayered TMDs nanocrystals could be the tandem intercalation [94] and potassium intercalation and disintegrating routes $[31,33]$. The former requires a small size and high crystallinity of the row material, and the latter is limited by the violent reaction (need additional safe controls) between the potassium and solvent $\left(\mathrm{EtOH} / \mathrm{H}_{2} \mathrm{O}\right)$. Besides, nanocrystals from these approaches were mainly $\mathrm{iH}$ phase, which is unfavorable for direct uses in high-performing energy storage devices, i.e. a fast energy storage device requires high electrical conductivity of the active material. In energy storage applications, the $2 \mathrm{D}$ TMDs may need to be combined with other materials, doped and defected further for better performances (e.g. higher capacity, stability and electrical conductivity). Therefore, various techniques beyond just the fabrication of the pure $2 \mathrm{D}$ TMDs are sought after for future development in this field, which will be further introduced in the next section.

\section{Summary and Prospect}

To satisfy the increasing demands for higher energy and power densities, along with the demand for other key features (e.g. long life-time, high safety and low cost), the energy storage techniques of both the supercapacitor and the secondary battery need to be improved. For such purposes, techniques such as the modification of traditional electrode materials and the energy storage pathways (e.g. energy storage beyond the "Li-ion") have been tested, which are not considered really successful. By contrast, recently developed 2D thin TMDs are considered to be more promising in improving many aspects of both supercapacitors and secondary batteries, owing at least to the following reasons:

- They have a thin structure similar to graphene, and could offer ideal super short electron transport length and small ion transport distance for the fast charge/discharge; Full 2D TMDs could participate in energy storage processes, increasing energy density and reducing manufacturing costs;

- Compared with traditional electrode materials (e.g. bulk TMDs, graphite and even graphene), the electrochemical behaviours of the surface of $2 \mathrm{D}$ TMDs can be both "Faradaic" and "Non-Faradaic" with higher adsorption energy and lower ion diffusion barriers, improving energy, power and cycling performances;

- In multilayered 2D TMDs, the intercalation between the interlayers is still a very fast quasi-2D process, ensuring a fast charge/discharge process. Energy storage with larger metal ions beyond $\mathrm{Li}^{+}$is also appropriate in these $2 \mathrm{D}$ TMDs owing to their larger interlayer space;
- They have interesting catalytically active edges which can be appropriately developed for energy storage, i.e. by introducing conversion reactions;

- The flexibility, the large EASA, the high surface tunability and rich coordination sites of $2 \mathrm{D}$ TMDs can be fully utilized to improve the areal and volumetric capacities of small and thin flexible devices which are expected to be some of the key features of future energy storage devices.

However, the energy storage research on the $2 \mathrm{D}$ TMDs is still at its very early stage. Relating device demonstrations based on purely monolayered or thin layered TMDs ( $<5$ layers) are rather limited. Table 1 summarizes the electrochemical performance of some recently developed $2 \mathrm{D}$-like (most are not thin enough) TMDs in energy storage. Most of these performances are still far below than the future demand or their theoretical ones, which is mainly due to the reasons:

- Many TMDs (particularly the $1 \mathrm{H} / 2 \mathrm{H}$ phases) in energy storage devices are not thin enough. How to fabricate the strictly monolayered TMDs with high yield at large scale is still a challenge;

- Most 2D 1T-TMDs are thermally unstable. Techniques for the stabilization of these $1 T$ TMDs with high electrical conductivity have not been well developed;

- Electrical conductivity of the most stable $1 \mathrm{H} / 2 \mathrm{H}$ TMDs is too poor to afford the application in high-performing energy storage devices.

There are several suggestions that may be followed for future improvements. As we know, the most 1T TMDs are metallic with high electrical conductivity [21], which in principle can be successfully used in building energy storage devices with high power performances. However, techniques are still required to improve both the phase yield (e.g. lower than $70 \%$ of the chemical exfoliation method $[37,91])$ and the stability of $1 \mathrm{~T}$ TMDs. Improvement on the phase yield can be realized by the stabilization of the 1T TMDs which is also imperative for durable and reversible energy storage operations. Several investigations suggest that 1T TMDs can be stabilized by suitable chemical doping [187-189]. Nevertheless, how these chemical modifications affect the electrochemical performances (e.g. binding energy with the ions, the ion diffusion barrier, the electrical conductivity and the surface wettability) of $1 \mathrm{~T}$ TMDs is still unclear, which should be established correspondingly. Beyond the $1 \mathrm{~T}$ TMDs, some stable $2 \mathrm{D}$ ternary sulfides (e.g. the $\mathrm{NiCO}_{2} \mathrm{~S}_{4}$ and $\mathrm{CoNi}_{2} \mathrm{~S}_{4}$ ) are also highly conducting [8o-82]. Nevertheless, the fabrication of ultrathin $2 \mathrm{D}$ ternary sulfides (e.g. down to the thickness of 1-2 $\mathrm{nm}$ ) is still challenging, which should be appropriately improved to reduce the thickness for more interesting applications in energy storage devices.

For the most stable $1 \mathrm{H} / 2 \mathrm{H}$ mono- and few-layered TMDs, the building of some hybrid structures to secure the rapid charge transfer process is highly recommended, i.e. building the vertically aligned (on graphene or other conducting materials) heterostructure of semiconducting TMDs thin layers and their oxide counterparts (e.g. $\mathrm{MoS}_{2}$ on $\mathrm{MoO}_{2}$ ) with higher electrical conductivity. Like the vertically aligned electrode (Fig. $\mathbf{7 b}$ ), this structure can fully apply the conducting transition metal oxides to inject the charge from the substrate to the TMD layers. The key factor here would be the controlling growth/fabrication of the heterostructure interstitially stacked by different ultra-thin nanosheets. More convenient approach- 
es could be including graphene and $2 \mathrm{D}$ TMDs materials (e.g. monolayered nanocrystals) into a hybrid structure with intimate contact (e.g. via strong physical and chemical interactions). In this case, ${ }_{3} \mathrm{D}-\mathrm{G}$ can be used as a support of $2 \mathrm{D}$ TMD nanocrystals (loaded on the channel of $3 \mathrm{D}-\mathrm{G}$ ) to ensure the efficient charge transfer between the electrode and the surface of the $2 \mathrm{D}$ TMDs, and also to provide a porous channel for efficient mass transfer. Alternatively, a flat layer-by-layer stacked hybrid structure of graphene and 2D TMDs (e.g. monolayered sheets or nanocrystals) could also be considered to avoid the inefficient electron hopping between the layers of TMDs. A technique issue here is to secure the strong bond between the TMD materials (e.g. monolayered nanocrystals) and the graphene. This structure would also be capable of providing larger interlayers for energy storage of large metal ions beyond the $\mathrm{Li}^{+}$(e.g. $\mathrm{Na}^{+}$and $\mathrm{K}^{+}$). To realize such conceptual devices with high performances, the size and the stacking limit of the $2 \mathrm{D}$ TMDs on the graphene sheet would need to be optimized. As for a higher loading of the active TMDs on graphene (for higher energy densities), heterostructures of $2 \mathrm{D}$ TMDs and electrochemical conducting thin materials may be more promising to be considered for the rapid charge transfer. This structure, in principle, can be formed by the sulfuration of thin $\mathrm{MoO}_{2}$ and $\mathrm{MoO}_{3}$ nanocrystals.

Except the above works, other factors, such as the mechanical strength of the hybrid structure (especially the $3 \mathrm{D}$ hybrid structure) should also be considered to afford robust energy storage performance (e.g. in flexible devices). For such a purpose, the functionalization of the $3 \mathrm{D}$ graphene channels with a thin electrical conducting polymer layer is suggested, which is feasible by adapting the similar approach established previously [190]. Besides the above discussions, future works in this field can also involve other strategies to improve the energy storage performance, which may include the chemical doping/modification of both the surface and the edge (to tune the charge mobility and catalytic activity) [75, 187-189], the building of van der Waals heterostructures [40, 157-159] and the creation of Janus $2 \mathrm{D}$ TMDs $[38,39,156]$. It also includes the development of the catalytically active site (for metal-air batteries) and the demonstration of the Li-S battery by using the monolayered TMDs (e.g. $\mathrm{MoS}_{2}$ ) nanocrystals with rich edge and activated surface sites (e.g. by surface $S$ depletion [31]). Nevertheless, before these can be success, both the theoretical and experimental understanding of the modified $2 \mathrm{D}$ TMDs in energy storage should be well developed. Understanding of the energy storage mechanism of the $2 \mathrm{D}$ TMDs can be realized by investigating difference of the redox peak potentials, establishing the relationship between the response current and the sweep rate, and quantifying the relative contribution of the capacitive and diffusion-limited process of the energy storage devices, which have been well established previously [191]. Besides, recent development suggests that the electrochemical tests building on the micro-fabrication and micro-cell could be adapted to reveal the pure mechanism by avoiding influences from other factors, although it has not been well used in this field $[171,192]$.

In summary, this mini review summarized challenges facing current supercapacitor and secondary battery technologies. How and why the $2 \mathrm{D}$ TMDs can perform perfectly in these devices are discussed. From all these discussions, it can be reasonably expected that 2D TMDs would be highly promising in improving both the supercapacitor and secondary battery. Nevertheless, several technical weaknesses are still need to be improved, including the fabrication and modification techniques of the materials, the design and building of hybrid structures we have outlined. This review provides deep insight into developing future high-performance energy storage devices by exploring the various merits of $2 \mathrm{D}$ TMDs.

\section{ASSOCIATED CONTENT}

\section{AUTHOR INFORMATION}

\section{Corresponding Author}

*junc@uow.edu.au

*s.zhang@exeter.ac.uk

\section{ACKNOWLEDGEMENTS}

Funding from the Australian Research Council (CE 140100012 and DP170102320) and UOW VC Fellowship are gratefully acknowledged. The authors would like to thank the Australian National Fabrication Facility - Materials node for facility access.

\section{Author Contributions}

This paper was prepared by Dr LL with the assistance of Dr WL and Dr YL. Prof. JC, Prof. SZ and Prof GW have provided constructive suggestions and drafted the manuscript with LL.

\section{Notes}

The authors declare no competing financial interests.

\section{REFERENCES}

[1] W.A. Braff, J.M. Mueller, J.E. Francik, Value of storage technologies for wind and solar energy. Nat. Clim. Change 6 (2016) 964969. https://doi.org/10.1038/nclimate3045.

[2] J.R. Miller, P. Simon, Electrochemical capacitors for energy management. Science 321 (2008) 651-652. https://doi.org/10.1126/science.1158736.

[3] H, Marzougui, M. Amari, A. Kadri, F. Bacha, J. Ghouili, Energy management of fuel cell/battery/ultracapacitor in electrical hybrid vehicle. Int. J. Hydrogen Energy. 65 (2017) 6592-66o1. https://doi.org/10.1016/j.ijhydene.2016.09.19o.

[4] A. Farmann, W. Waag, D.U. Sauer, Application-specific electrical characterization of high power batteries with lithium titanate anodes for electric vehicles. Energy 112 (2016) 294-306. https://doi.org/10.1016/j.energy.2016.06.088.

[5] P. Patel, New battery tech launches in drones. IEEE Spectrum 55 (2018) 7-9. https://doi.org/10.1109/MSPEC.2018.8389171.

[6] L. Donaldson, Breakable electrode design brings safer batteries for electric cars. Mater. Today 21 (2018) 199. https://doi.org/10.1016/j.mattod.2018.03.018.

[7] T.P. Natins, The battery business: lithium availability and the growth of the global electric car industry. Extr. Ind. Soc. 4 (2017) 321-328. https://doi.org/10.1016/j.exis.2017.01.013.

[8] J. Tollefson, Car industry: charging up the future. Nature 456 (2008) 436-440. https://doi.org/10.1038/456436a.

[9] S. Saxena, G. Sanchez, M. Pecht, Batteries in portable electronic devices: a users's perspective. IEEE Ind. Electron. M. 11 (2017) 35 44. https://doi.org/10.1109/MIE.2017.2688483.

[10] F. Xue, Z. Ling, Y. Yang, X. Miao, Design and implementation of novel smart battery management system for FPGA based portable electronic devices. Energies 10 (2017) 264. https://doi.org/10.339o/en1o030264.

[11] A. Ishida, M. Fujii, T. Fujimoto, S. Sasaki, I. Yanagisawa, H. Tani, M. Tokeshi, A portable liquid chromatograph with a batteryoperated compact electroosmotic pump and a microfluidic chip device with a reversed phase packed column. Anal. Sci. 31 (2015) 116301169. https://doi.org/10.2116/analsci.31.1163.

[12] S. Zhang, B. Yin, C. Liu, Z. Wang, D. Gu, A lightweight, compressible and portable sponge-based supercapacitor for future power supply. Chem. Eng. J. 349 (2018) 509-521. https://doi.org/10.1016/j.cej.2018.05.125. 
[13] A. Scalia, F. Bella, A. Lamberti, S. Bianco, C. Gerbaldi, E. Tresso, C.F. Pirri, A flexible and portable powerpack by solid-state supercapacitor and dye-sensitized solar cell integration. J. Power Sources 359 (2017) 311-321. https://doi.org/10.1016/j.jpowsour.2017.05.072.

[14] J.P. Esquivel, P. Alday, O.A.Ibrahim, B. Fernandez, E. Kjeang, N. Sabate, A metal-free and biotically degradable battery for portable single-use applications. Adv. Energy Mater. 7 (2017) 1700275. https://doi.org/10.1002/aenm.201700275.

[15] C. Zhao, W. Zheng, A review for aqueous electrochemical supercapacitors. Front. Energy Res. 3 (2015) 23. https://doi.org/10.3389/fenrg.2015.00023.

[16] S. Faraji, F.N. Ani, The development supercapacitor from activated carbon by electroless plating-a review. Renew. Sust. Energ. Rev. 42 (2015) 823-834. https://doi.org/10.1016/j.rser.2014.10.068.

[17] A. Tyagi, K.M. Tripathi, R.K. Gupta, Recent progress in microscale energy storage devices and future aspects. J. Mater. Chem. A 3 (2015) 22507-22541. https://doi.org/10.1039/C5TA05666G.

[18] Y. Liu, K. He, G. Chen, W.R. Leow, X. Chen, Nature-inspired structural materials for flexible electronic devices. Chem. Rev. 117 (2017) 12893-12941. https://doi.org/10.1021/acs.chemrev.7boo291.

[19] L. Li, Z. Wu, S. Yuan, X. Zhang, Advances and challenges for flexible energy storage and conversion devices and systems. Energy Environ. Sci. 7 (2014) 2101-2122. https://doi.org/10.1039/C4EEoo318G.

[2o] W. Choi, N. Choudhary, G.H. Han, J. Park, D. Akinwande, Y.H. Lee, Recent development of two-dimensional transition metal dichalcogenides and their applications. Mater. Today 20 (2017) 116-13o. https://doi.org/10.1016/j.mattod.2016.10.002.

[21] M. Chhowalla, H.S. Shin, G. Eda, L.-J. Li, K.P. Loh, H. Zhang, The chemistry of two-dimensional layered transition metal dichalcogenide nanosheets. Nat. Chem. 5 (2013) 263-275. https://doi.org/10.1038/nchem.1589.

[22] F. Bonaccorso, L. Colombo, G. Yu, M. Stoller, V. Tozzini, A.C. Ferrari, R.S. Ruoff, V. Pellegrini, Graphene, related twodimensional crystals, and hybrid systems for energy conversion and storage. Science 347 (2015) 1246501. https://doi.org/10.1126/science.1246501.

[23] K. Kato, F.N. Sayed, G. Babu, P.M. Ajayan, All 2 D materials as electrodes for high power hybrid energy storage applications. $2 \mathrm{D}$ Mater. 5 (2018) 025016. https://doi.org/10.1088/2053-1583/aaad29.

[24] N. Choudhary, M.A. Islam, J.H. Kim, T.-J. Ko, A. Schropp, L. Huntado, D. Weitzman, L. Zhai, Y. Jung. Two-dimensional transition metal dichalcogenide hybrid materials for energy applications. Nanotoday 19 (2019) 16-40. https://doi.org/10.1016/j.nantod.2018.02.007.

[25] M. Chhowalla, D. Voiry, J. Yang, H.S. Shin, K.P. Loh, Phaseengineered transition-metal dichalcogenides for energy and electronics. MRS Bulletin 40 (2015) 585-591. https://doi.org/10.1557/mrs.2015.142.

[26] H. Li, Q. Yang, F. Mo, G. Liang, Z. Liu, Z. Tang, L. Ma, J. Liu, Z. Shi, C. Zhi, $\mathrm{MoS}_{2}$ nanosheets with expanded interlayer spacing for rechargeable aqueous Zn-Ion batteries. Energy Storage Mater. 11 (2018) https://doi.org/10.1016/j.ensm.2018.10.005.

[27] D. Yu, Q. Pang, Y. Gao, Y. Wei, C. Wang, G. Chen, F. Du, Hierarchical flower-like $\mathrm{VS}_{2}$ nanosheets - A high rate-capacity and stable anode material for sodium-ion battery. Energy Storage Mater. 11 (2018) 1-7. https://doi.org/10.1016/j.ensm.2017.09.002.

[28] C. Tsai, F. Abild-Pedersen, J.K. Nørskov, Tuning the $\mathrm{MoS}_{2}$ edgesite activity for hydrogen evolution via support interactions. Nano Lett. 14 (2014) 1381-1387. https://doi.org/10.1021/nl404444k.

[29] C. Tsai, K. Chan, F. Abild-Pedersen, J.K. Nørskov, Active edge sites in $\mathrm{MoSe}_{2}$ and $\mathrm{WSe}_{2}$ catalysts for the hydrogen evolution reaction: a density functional study. Phys. Chem. Chem. Phys. 16 (2014) 13156-13164. https://doi.org/10.1039/C4CPo1237B.

[30] C. Tsai, K. Chan, J.K. Nørskov, F. Abild-Pedersen, Theoretical insights into the hydrogen evolution activity of layered transition metal dichalcogenides. Sur. Sci. 640 (2015) 133-140. https://doi.org/10.1016/j.susc.2015.01.019.

[31] L. Lin, N. Miao, Y. Wen, S. Zhang, P. Ghosez, Z. Sun, D.A. Allwood, Sulphur depleted monolayered molybdenum disulfide nanocrystals for superelectrochemical hydrogen evolution reac- tion, ACS Nano 10 (2016) 8929-8937.

https://doi.org/10.1021/acsnano.6bo4904.

[32] L. Lin, N. Miao, J. Huang, S. Zhang, Y. Zhu, D.W. Horsell, P. Ghosez, Z. Sun, D.A. Allwood, A photocatalyst of sulphur depleted monolayered molybdenum sulfide nanocrystals for dye degradation and hydrogen evolution reaction. Nano Energy 38 (2017) 544-552. https://doi.org/10.1016/j.nanoen.2017.06.008.

[33] L. Lin, Y. Xu, S. Zhang, I.M. Ross, A.C.M. Ong, D.A. Allwood, Fabrication of luminescent monolayered tungsten dichalcogenides quantum dots with giant spin-valley coupling. ACS Nano 7 (2013), 8214-8223. https://doi.org/10.1021/nn403682r.

[34] K.F. Mak, C. Lee, J. Hone, J. Shan, T.F. Heinz, Atomically thin $\mathrm{MoS}_{2}$ : a new direct-gap semiconductor. Phys. Rev. Lett. 105 (2010) 136805. https://doi.org/10.1103/PhysRevLett.105.136805.

[35] E.J. Sie, C. Lui, Y.-H. Lee, L. Fu, J. Kong, N. Gedik, Large, valleyexclusive bloch-siegert shift in monolayer $\mathrm{WS}_{2}$. Science 355 (2017), 1066-1069. https://doi.org/10.1126/science.aal2241.

[36] Y. Yu, S.-Y. Huang, Y. Li, S.N. Steinmann, W. Yang, L. Cao, Layerdependent electrocatalysis of $\mathrm{MoS}_{2}$ for hydrogen evolution. Nano Lett. 14 (2014) 553-558. https://doi.org/10.1021/nl403620g.

[37] M. Acerce, D. Voiry, M. Chhowalla, Metallic iT phase $\mathrm{MoS}_{2}$ nanosheets as supercapacitor electrode materials. Nat. Nanotechnol. 10 (2015) 313-318. https://doi.org/10.1038/nnano.2015.40.

[38] A.-Y. Lu, H. Zhu, J. Xiao, C.-P. Chuu, Y. Han, M.-H. Chiu, C.-C. Cheng, C.-W. Yang, K.-H. Wei, Y. Yang, Y. Wang, D. Sokaras, D. Nordlund, P. Yang, D.A. Muller, M.-Y. Chou, X. Zhang, L.-J. Li, Janus monolayers of transition metal dichalcogenides. Nat. Nanotechnol. 12 (2017) 744-749. https://doi.org/10.1038/nnano.2017.100.

[39] W. Shi, Z. Wang, Mechanical and electronic properties of Janus monolayer transition metal dichalcogenides. J. Phys: Condens. Mat. 30 (2018) 215301. https://doi.org/10.1088/1361-648X/aabd59.

[40] D. Vikraman, S. Hussain, K. Akbar, L. Truong, A. Kathalingam, S.H. Chun, J. Jung, H.J. Park, H.-S. Kim, Improved hydrogen evolution reaction performance using $\mathrm{MoS}_{2}-\mathrm{WS}_{2}$ heterostructures by physicochemical process. ACS Sustain. Chem. Eng. 6 (2018) 84008409. https://doi.org/10.1021/acssuschemeng.8boo524.

[41] P. Simon, Y. Gogotsi, Materials for electrochemical capacitors. Nat. Mater. 7 (2008) 845-854. https://doi.org/10.1038/nmat2297.

[42] H. Helmholtz, Ueber einige Gesetze der Vertheilung elektrischer Ströme in körperlichen Leitern, mit Anwendung auf die thierischelektrischen Versuche. Ann. Phys. Chem. 1853, 165, 353-377. https://doi.org/10.1002/andp.18531650702.

[43] M. Favaro, B. Jeong, P.N. Ross, J. Yano, Z. Hussain, Z. Liu, E.J. Crumlin, Unravelling the electrochemical double layer by direct probing of the solid/liquid interface. Nat. Commun. 2016, 7, 12695. https://doi.org/10.1038/ncomms12695.

[44] Y. Yan, Y. Luo, J. Ma, B. Li, H. Xue, H. Pang, Facile synthesis of vanadium metal-organic frameworks for high-performance supercapacitors. Small 14 (2018) 1801815. https://doi.org/10.1002/smll.201801815.

[45] D.N. Futaba, T. Yamada, T. Hiraoka, Y. Hayamizu, Y. Kakudate, O. Tanaike, H. Hatori, M. Yumura, S. Iijuma, Shape-engineerable and highly densely packed single-walled carbon nanotubes and their application as super-capacitor electrodes. Nat. Mater. 5 (2006) 987-994. https://doi.org/10.1038/nmat1782.

[46] C. Portet, J. Chmiola, Y. Gogotsi, S. Park, K. Lian, Electrochemical characterizations of carbon nanomaterials by the cavity microelectrode technique. Electrochim. Acta 53 (2008) 7675-768o. https://doi.org/10.1016/j.electacta.2008.05.019.

[47] X. Lang, A. Hirata, T. Fujita, M. Chen, Nanoporous metal/oxide hybrid electrodes for electrochemical supercapacitors. Nat. Nanotechnol. 6 (2011) 232-236. https://doi.org/10.1038/nnano.2011.13.

[48] J. Zhou, J. Lian, L. Hou, J. Zhang, H. Gou, M. Xia, Y. Zhao, T.A. Strobel, L. Tao, F. Gao, Ultrahigh volumetric capacitance and cyclic stability of fluorine and nitrogen co-doped carbon microspheres. Nat. Commun. 6 (2015) 8503. https://doi.org/10.1038/ncomms9503.

[49] R. Bi, X. Wu, F. Cao, L. Jiang, Y. Guo, L. Wan, Highly dispersed $\mathrm{RuO}_{2}$ nanoparticles on carbon nanotubes: facile synthesis and enhanced supercapacitance performance. J. Phys. Chem. C 114 (2010) 2448-2451. https://doi.org/10.1021/jp9116563. 
[5o] N.L. Wu, Nanocrystalline oxide supercapacitors. Mater. Chem. Phys. 75 (2002) 6-11. https://doi.org/10.1016/So254-0584(02)000226.

[51] T. Brezesinski, J. Wang, S. H. Tolbert, B. Dunn, Ordered mesoporous $\alpha-\mathrm{MoO}_{3}$ with iso-oriented nanocrystalline walls for thin-film pseudocapacitors. Nat. Mater. 9 (2010) 146-151. https://doi.org/10.1038/nmat2612.

[52] M. Toupin, T. Brousse, D. Belanger, Charge storage mechanism of $\mathrm{MnO}_{2}$ electrode used in aqueous electrochemical capacitor. Chem. Mater. 16 (2004) 3184-319o. https://doi.org/10.1021/cmo49649j.

[53] Y. He, W. Chen, X. Li, Z. Zhang, J. Fu, C. Zhao, E. Xie, Freestanding three-dimensional graphene $/ \mathrm{MnO}_{2}$ composite networks as ultralight and flexible supercapacitor electrodes. ACS Nano 7 (2013) 174-182. https://doi.org/10.1021/nn304833s.

[54] Y. Yan, B. Li, W. Guo, H. Pang, H. Xue, Vanadium based materials as electrode materials for high performance supercapacitors. J.

Power Sources 329 (2016) 148-169.

https://doi.org/10.1016/j.jpowsour.2016.08.039.

[55] T.S. Tran, K.M. Tripathi, B.N. Kim, I.-K. You, B.J. Park, Y.H. Han, T. Kim, Three-dimensionally assembled graphene $/ \alpha-\mathrm{MnO}_{2}$ nanowire hybrid hydrogels for high performance supercapacitors. Mater. Res. Bull. 96 (2017) 395-404. https://doi.org/10.1016/j.materresbull.2017.04.012.

[56] Y. Zhu, S. Murali, M.D. Stoller, K.J. Ganesh, W. Cai, P.J. Ferreira, A. Pirkle, R.M. Wallace, K.A. Cychosz, M. Thommes, D. Su, E.A. Stach, R.S. Ruoff, Carbon-based supercapacitors produced by activation of graphene. Science 332 (2011) 1537-1541. https://doi.org/10.1126/science.120077o.

[57] S. Chabi, C. Peng, D. Hu, Y. Zhu, Ideal three-dimensional electrode structures for electrochemical energy storage. Adv. Mater. 26 (2014) 2440-2445. https://doi.org/10.1002/adma.201305095.

[58] M.F. Ei-Kady, M. Ihns, M. Li, J.Y. Hwang, M.F. Mousavi, L. Chaney, A.T. Lech, R.B. Kaner, Engineering three-dimensional hybrid supercapacitors and microsupercapacitors for highperformance integrated energy storage. Proc. Natl. Acad. Sci. U. S. A. 112 (2015) 4233-4238. https://doi.org/10.1073/pnas.1420398112.

[59] T. Lin, I. Chen, F. Liu, C. Yang, H. Bi, F. Xu, F. Huang, Nitrogendoped mesoporous carbon of extraordinary capacitance for electrochemical energy storage. Science 350 (2015) 1508-1513. https://doi.org/10.1126/science.aab3798.

[6o] T. Kim, G. Jung, S. Yoo, K.S. Suh, R.S. Ruoff, Activated graphenebased carbon as supercapacitor electrodes with macro- and mesopores. ACS Nano 7 (2013) 6899-6905. https://doi.org/10.1021/nn402077v.

[61] Z. Wu, A. Winter, L. Chen, Y. Chen, Y. Sun, A. Turchanin, X. Feng, K. Müllen, Three-dimensional nitrogen and boron co-doped graphene for high-performance all-solid-state supercapacitors. Adv. Mater. 24 (2012) 5130-5135. https://doi.org/10.1002/adma.201201948.

[62] C. Zhu, T. Liu, F. Qian, T.Y.-J. Han, E.B. Duoss, J.D. Kuntz, C.M. Spadaccini, M.A. Worsley, Y. Li, Supercapacitors based on threedimensional hierarchical graphene aerogels with periodic macropores. Nano Lett. 16 (2016) 3448-3456. https://doi.org/10.1021/acs.nanolett.5bo4965.

[63] X. Cao, Y. Shi, W. Shi, G. Lu, X. Huang, Q. Yan, Q. Zhang, H. Zhang, Preparation of novel $3 \mathrm{D}$ graphene networks for supercapacitor applications. Small 7 (2011) 3163-3168. https://doi.org/10.1002/smll.20110099o.

[64] X. Wang, Y. Zhang, C. Zhi, X. Wang, D. Tang, Y. Xu, Q. Weng, X. Jiang, M. Mitome, D. Golberg, Y. Bando, Three-dimensional strutted graphene grown by substrate-free sugar blowing for highpower-density supercapacitors. Nat. Commun. 4 (2013) 2905. https://doi.org/10.1038/ncomms3905.

[65] H. Bi, T. Lin, F. Xu, Y. Tang, Z. Liu, F. Huang, New graphene form of nanoporous monolith for excellent energy storage. Nano Lett. 16 (2016) 349-354. https://doi.org/10.1021/acs.nanolett.5bo3923.

[66] L. Zhang, F. Zhang, X. Yang, G. Long, Y. Wu, T. Zhang, K. Leng, Y. Huang, Y. Ma, A. Yu, Y. Chen, Porous 3D graphene-based bulk materials with exceptional high surface area and excellent conductivity for supercapacitors. Sci. Rep. 3 (2013) 1408. https://doi.org/10.1038/srepo1408.
[67] Y. Liao, Y. Huang, D. Shu, Y. Zhong, J. Han, C. He, J. Zhong, X. Song, Three-dimensional nitrogen-doped graphene hydrogels prepared via hydrothermal synthesis as high-performance supercapacitor materials. Electrochimica Acta 194 (2016) 136-142. https://doi.org/10.1016/j.electacta.2016.02.067.

[68] D. Liu, C. Fu, N. Zhang, H. Zhou, Y. Kuang, Three-dimensional porous nitrogen doped graphene hydrogel for high energy density supercapacitors. Electrochimica Acta 213 (2016) 291-297. https://doi.org/10.1016/j.electacta.2016.07.131.

[69] F. Wang, M. Zheng, L. Ma, Q. Li, J. Song, Y. You, L. Ma, W. Shen, Nickel skeleton three-dimensional nitrogen doped graphene nanosheets/nanoscrolls as promising supercapacitor electrodes. Nanotechnology 28 (2017) 365402. https://doi.org/10.1088/13616528/aa79e4.

[7o] Y. Du, G. Zhu, K. Wang, Y. Wang, C. Wang, Y. Xia, Si/graphene composite prepared by magnesium thermal reduction of $\mathrm{SiO}_{2}$ as anode material for lithium-ion batteries. Electrochem. Commun. 36 (2013) 107-110. https://doi.org/10.1016/j.elecom.2013.09.019.

[71] H. Zhang, K. Wang, X. Wu, Y. Jiang, Y. Zhai, C. Wang, X. Wei, J. Chen, $\mathrm{MoO}_{2} / \mathrm{Mo}_{2} \mathrm{C}$ heteronanotubes function as highperformance Li-Iion battery electrode. Adv. Funct. Mater. 24 (2014) 3399-3404. https://doi.org/10.1002/adfm.201303856.

[72] J.M. Soon, K.P. Loh, Electrochemical double-layer capacitance of $\mathrm{MoS}_{2}$ nanowall films. Electrochem. Solid-State Lett. 10 (2007) A250-A254. https://doi.org/10.1149/1.2778851.

[73] L. Cao, S. Yang, W. Gao, Z. Liu, Y. Gong, L. Ma, G. Shi, S. Lei, Y. Zhang, S. Zhang, R. Vajtai, P.M. Ajayan, Direct laser-patterned micro-supercapacitors from paintable $\mathrm{MoS}_{2}$ films. Small 9 (2013) 2905-2910. https://doi.org/10.1002/smll.201203164.

[74] D. Voiry, A. Goswami, R. Kappera, C. de C. Castro e Silva, D. Kaplan, T. Fujita, M. Chen, T. Asefa, M. Chhowalla, Covalent functionalization of monolayered transition metal dichalcogenides by phase engineering. Nat. Chem. 7 (2015) 45-49. https://doi.org/10.1038/nchem.2108.

[75] Q. Tang, D. Jiang, Stabilization and band-gap tuning of the $1 \mathrm{~T}$ $\mathrm{MoS}_{2}$ monolayer by covalent functionalization. Chem. Mater. 27 (2015) 3743-3748. https://doi.org/10.1021/acs.chemmater.5boog86.

[76] Y. Yin, Y. Zhang, T. Gao, T. Yao, X. Zhang, J. Han, X. Wang, Z. Zhang, P. Xu, P. Zhang, X. Cao, B. Song, S. Jin, Synergistic phase and disorder engineering in $1 \mathrm{~T}-\mathrm{MoSe}_{2}$ nanosheets for enhanced hydrogen-evolution reaction. Adv. Mater. 29 (2017) 1700311. https://doi.org/10.1002/adma.201700311

[77] M. Piao, J. Chu, X. Wang, Y. Chi, H. Zhang, C. Li, H. Shi, M.-K. Joo, Hydrothermal synthesis of stable metallic $1 \mathrm{~T}$ phase $\mathrm{WS}_{2}$ nanosheets for thermoelectric application. Nanotechnology 29 (2018) 025705. https://doi.org/10.1088/1361-6528/aagbfe.

[78] A. Ambrosi, Z. Sofer, M. Pumera, $2 \mathrm{H} \rightarrow 1 \mathrm{~T}$ phase transition and hydrogen evolution activity of $\mathrm{MoS}_{2}, \mathrm{MoSe}_{2}, \mathrm{WS}_{2}$ and $\mathrm{WSe}_{2}$ strongly depends on the $\mathrm{MX}_{2}$ composition. Chem. Commun. 51 (2015) 8450-8453. https://doi.org/10.1039/C5CCoo8o3D.

[79] H. Chen, J. Jiang, L. Zhang, H. Wan, T. Qi, D. Xia, Highly conductive $\mathrm{NiCO}_{2} \mathrm{~S}_{4}$ urchin-like nanostructures for high-rate pseudocapacitors. Nanoscale 5 (2013) 8879-8883. https://doi.org/10.1039/C3NRo2958A.

[8o] C, Xia, P. Li, A.N. Gandi, U. Schwingenshlögl, H.N. Alshareef, Is $\mathrm{NiCo}_{2} \mathrm{~S}_{4}$ really a semiconductor? Chem. Mater. 27 (2015) 64826485. https://doi.org/10.1021/acs.chemmater.5bo1843.

[81] R.J. Bouchard, P.A. Russo, A. Wold, Preparation and electrical properties of some thiospinels. Inorg. Chem. 4 (1965) 685-688. https://doi.org/10.1021/ic50027ao19.

[82] I.M.EI Radaf, S.S. Fouad, A.M. Ismail, G.B. Sakr, Influence of spray time on the optical and electrical properties of $\mathrm{CoNi}_{2} \mathrm{~S}_{4}$ thin films. Mater. Res. Express 5 (2018) 046406. https://doi.org/10.1088/20531591/aabaoa.

[83] V.H. Nguyen, J.-J. Shim, In situ growth of hierarchical mesoporous $\mathrm{NiCo}_{2} \mathrm{~S}_{4} @ \mathrm{MnO}_{2}$ arrays on nickel foam for high-performance supercapacitors. Electrochim. Acta 166 (2015) 302-309. https://doi.org/10.1016/j.electacta.2015.03.069.

[84] L. Mei, T. Yang, C. Xu, M. Zhang, L. Chen, Q. Li, T. Wang, Hierarchical mushroom-like $\mathrm{CoNi}_{2} \mathrm{~S}_{4}$ arrays as a novel electrode material for supercapacitors. Nano Energy 3 (2014) 36-45. https://doi.org/10.1016/j.nanoen.2013.10.004. 
[85] T. Peng, Z. Qian, J. Wang, D. Song, J. Liu, Q. Liu, P. Wang, Construction of mass-controllable mesoporous $\mathrm{NiCo}_{2} \mathrm{~S}_{4}$ electrodes for high performance supercapacitors. J. Mater. Chem. A 2 (2014) 19376-19382. https://doi.org/10.1039/C4TAo4246H.

[86] Z. Li, D. Zhao. C. Xu, J. Ning, Y. Zhong, Z. Zhang, Y. Wang, Y. Hu, Reduced $\mathrm{CoNi}_{2} \mathrm{~S}_{4}$ nanosheets with enhanced conductivity for high-performance supercapacitors. Electrochim. Acta 278 (2018) 33-41. https://doi.org/10.1016/j.electacta.2018.05.030.

[87] W. Hu, R. Chen, W. Xie, L. Zou, N. Qin, D. Bao, $\mathrm{CoNi}_{2} \mathrm{~S}_{4}$ nanosheet arrays supported on nickel foams with ultrahigh capacitance for aqueous asymmetric supercapacitor applications. ACS Appl. Mater. Interfaces 6 (2014) 19318-19326. https://doi.org/10.1021/am5053784.

[88] G.A. Muller, J.B. Cook, H.-S. Kim, S.H. Tolbert, B. Dunn, High performance pseudocapacitor based on $2 \mathrm{D}$ layered metal chalcogenide nanocrystals. ACS Nano 15 (2015) 1911-1917. https://doi.org/10.1021/nl504764m.

[89] C. Tu, L. Lin, B. Xiao, Y. Chen, Highly efficient supercapacitor electrode with two-dimensional tungsten disulfide and reduced graphene oxide hybrid nanosheet. J. Power Sources 320 (2016) 7885. https://doi.org/10.1016/j.jpowsour.2016.04.083.

[9o] J. Shen, J. Wu, L. Pei, M.-T.F. Rodrigus, Z. Zhang, F. Zhang, X. Zhang, P.M. Ajayan, M. Ye, $\mathrm{CoNi}_{2} \mathrm{~S}_{4}$-graphene-2D-MoSe ${ }_{2}$ as an advanced electrode material for supercapacitors. Adv. Energy Mater. 6 (2016) 160034. https://doi.org/10.1002/aenm.201600341.

[91] C. Tan, Z. Luo, A. Chaturvedi, Y. Cai, Y. Du, Y. Gong, Y. Huang, Z. Lai, X. Zhang, L. Zheng, X. Qu, M.H. Goj, J. Wang, S. Han, X. Wu, L. Gu, C. Kloc, H. Zhang, Preparation of high-percentage iT-phase transition metal dichalcogenide nanodots for electrochemical hydrogen evolution. Adv. Mater. 30 (2018) 1705509. https://doi.org/10.1002/adma.201705509.

[92] H. Lin, R.Y. Tay, S.H. Tsang, X. Zhen, E.H. Teo, Controllable synthesis of highly luminescent boron nitride quantum dots, Small 11 (2015) 6491-6499. https://doi.org/10.1002/smll.201501632.

[93] S. Xu, D. Li, P. Wu, On-pot, facile, and versatile synthesis of monolayer $\mathrm{MoS}_{2} / \mathrm{WS}_{2}$ quantum dots as bioimaging probes and efficient electrocatalysts for hydrogen evolution reaction. Adv. Funct. Mater. 25 (2015) 1127-1136. https://doi.org/10.1002/adfm.201403863.

[94] S. Jeong, D. Yoo, M. Ahn, P. Miró, T. Heine, J. Cheon, Tandem intercalation strategy for single-layer nanosheets as an effective alternative to conventional exfoliation processes. Nat. Commun. 6 (2015) 5763. https://doi.org/10.1038/ncomms6763.

[95] L. Lin, S. Zhang, Creating high yield water soluble luminescent graphene quantum dots via exfoliating and disintegrating carbon nanotubes and graphite flakes. Chem. Commun. 48 (2012) 10177-

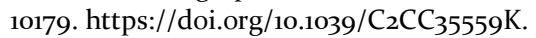

[96] L. Lin, Y. Xu, S. Zhang, I.M. Ross, A.C.M. Ong, D.A. Allwood, Fabrication and luminescence of monolayered boron nitride quantum dots. Small 10 (2014) 6o-65. https://doi.org/10.1002/smll.201301001.

[97] R. Chen, R. Luo, Y. Huang, F. Wu, L. Li, Advanced high energy density secondary batteries with multi-electron reaction materials. Adv. Sci. 3 (2016) 1600051. https://doi.org/10.1002/advs.201600051.

[98] K.M Abraham, Prospects and limits of energy storage in batteries. J. Phys. Chem. Lett. 6 (2015) 830-844. https://doi.org/10.1021/jz5026273.

[99] J.B. Goodenough, K.S. Park, The Li-ion rechargeable battery: a perspective. J. Am. Chem. Soc. 135 (2012) 1167-1176. https://doi.org/10.1021/ja3091438.

[10o] E.M. Garcia, H.A. Taroco, R.Z. Domingues, T. Matencio, S.L.A. Goncalves, Electrochemical recycling of cell phone Li-ion batteries: application as corrosion protector of AISI 430 stainless steel in artificial seawater. Ionics 22 (2016) 735-741. https://doi.org/10.1007/s11581-016-1691-4.

[101] S.A Goncalves, E.M. Garcia, H.A. Taroco, R.G. Teixeira, K.J. Guedes, H.F. Gorgulho, P.B. Martelli, A.P.L. Fernandes, Development of non-enzymatic glucose sensor using recycled cobalt from cell phone Li-ion batteries. Waste Manage. 46 (2015) 497-502. https://doi.org/10.1016/j.wasman.2015.08.026.

[102] D. Deng, Li-ion batteries: basis, progress, and challenges. Energy Sci. Eng. 3 (2015) 385-418. https://doi.org/10.1002/ese3.95.
[103] N.V. Sang, W. Choi, D.W. Kim, Non-isolated boost charger for the Li-ion batteries suitable for fuel cell powered laptop computers. J. Power Electron. 13 (2013) 31-39. https://doi.org/10.6113/JPE.2013.13.1.31.

[104] B. Lu, J. Liu, R. Hu, H. Wang, J. Li, M. Zhu, C@MoS_@PPy sandwich-like nanotube arrays as an ultrastable and high-rate flexible anode for Li/Na-ion batteries. Energy Storage Mater. 14 (2018) 118128. https://doi.org/10.1016/j.ensm.2018.02.022.

[105] J. Ma, E. Zhou, C. Fan, B. Wu, C. Lu, Z. Lu, J. Li, Endowing CuTCNQ with a new role: a high-capacity cathode for K-ion batteries. Chem. Commun. 54 (2018) 5578-5581. https://doi.org/10.1039/c8ccoo802g.

[106] K.V. Kravchyk, L. Piyeteau, R. Caputo, M. He, N.P. Stadie, M.I. Bodnarchuk, R.T. Lechner, M.V. Kovalenko, Colloidal bismuth nanocrystals as a model anode material for rechargeable Mg-ion batteries: atomistic and mesoscale insights. ACS Nano 12 (2018) 8297-8307. https://doi.org/10.1021/acsnano.8bo3572.

[107] S. He, K. Nielson, J. Luo, T. Liu, Recent advances on $\mathrm{MgCl}_{2}$ based electrolytes for rechargeable $\mathrm{Mg}$ batteries. Energy Storage Mater. 8 (2017) 184-188. https://doi.org/10.1016/j.ensm.2016.12.001.

[108] P. Wang, H. Chen, N. Li, X. Zhang, S. Jiao, W.-L. Song, D. Fang, Dense graphene papers: toward stable and recoverable Al-ion battery cathodes with high volumetric and areal energy and power density. Energy Storage Mater. 14 (2018) 103-111. https://doi.org/10.1016/j.ensm.2018.01.001.

[109] P. Gu, Y. Xu, Y. Zhao, W. Liu, H. Xue, H. Pang, Electrocatalysis of rechargeable non-lithium metal-air batteries. Adv. Mater. Interfaces 4 (2017) 1700589. https://doi.org/10.1002/admi.201700589.

[110] W. Lei, H. Liu, J. Xiao, Y. Wang, L. Lin, Moss-derived mesoporous carbon as bi-functional electrode materials for lithium-sulfur batteries and supercapacitors. Nanomaterials 9 (2019) 84 . https://doi.org/10.3390/nano9o10084.

[111] B. Gao, X. Li, K. Ding, C. Huang, Q. Li, P.K. Chu, K. Huo, Recent progress in nanostructured transition metal nitrides for advanced electrochemical energy storage. J. Mater. Chem. A 7 (2019) 14-37. https://doi.org/10.1021/10.1039/C8TAo576oE.

[112] Y. Xu, W. Li, G. Zhou, Z. Pan, Y. Zhang, A non-nucleophilic mono- $\mathrm{Mg}^{2+}$ electrolyte for rechargeable $\mathrm{Mg} / \mathrm{S}$ battery. Energy Storage Mater. 14 (2018) 253-257. https://doi.org/10.1016/j.ensm.2018.03.020.

[113] J.-K. Haung, M. Li, Y. Wan, S. Dey, M. Ostwal, D. Zhang, C.-W. Yang, C.-J. Su, U.-S. Jeng, J. Ming, A. Amassian, Z. Lai, Y. Han, S. Li, L.-J. Li, Functional two-dimensional coordination polymeric layer as a charge barrier in Li-S batteries. ACS Nano 12 (2018) 836843. https://doi.org/10.1021/acsnano.7bo8223.

[114] E. Yang, H. Ji, Y. Jung, Two-dimensional transition metal dichalcogenide monolayers as promising sodium ion battery anodes. J. Phys. Chem. C 119 (2015) 26374-2638o.

[115] G.A. Muller, J.B. Cook, H.-S. Kim, S.H. Tolbert, B. Dunn, High performance pseudocapacitor based on $2 \mathrm{D}$ layered metal chalcogenide nanocrystals. ACS Nano 15 (2015) 1911-1917. https://doi.org/10.1021/nl504764m.

[116] A. Samad, A. Shafique, Y.-H. Shin, Adsorption and diffusion of mono, di, and trivalent ions on two-dimensional $\mathrm{TiS}_{2}$. Nanotechnology 28 (2017) 17501. https://doi.org/10.1088/1361-6528/aa6536.

[117] B. Xu, L. Wang, H. Chen, J. Zhao, G. Liu, M. Wu, Adsorption and diffusion of lithium on $1 \mathrm{~T}-\mathrm{MoS}_{2}$ monolayer. Comp. Mater. Sci. 93 (2014) 86-9o. https://doi.org/10.1016/j.commatsci.2014.06.033.

[118] Y. Jiao, A. Mukhopadhyay, Y. Ma, L. Yang, A.M. Hafez, H. Zhu, Ion transport nanotube assembled with vertically aligned metallic $\mathrm{MoS}_{2}$ for high rate lithium-ion batteries. Adv. Energy Mater. 8 (2018) 1702779. https://doi.org/10.1002/aenm.201702779.

[119] N.S. Mikhaleva, M.A. Visotin, A.A. Kuzubov, Z.I. Popov, $\mathrm{VS}_{2}$ /graphene heterostructures as promising anode material for Li-ion batteries. J. Phys. Chem. C 121 (2017) 24179-24184. https://doi.org/10.1021/acs.jpcc.7bo763o.

[120] D. Wang, Y. Liu, X. Meng, Y. Wei, Y. Zhao, Q. Pang, G. Chen, Two-dimensional $\mathrm{VS}_{2}$ monolayers as potential anode materials for lithium-ion batteries and beyond: first-principles calculations. J. Mater. Chem. A 5 (2017) 21370-21377. https://doi.org/10.1039/C 7 TAo6944H. 
[121] L. Cai, Q. Zhang, J.P. Mwizerwa, H. Wan, X. Yang, X. Xu, X. Yao, Highly crystalline layered $\mathrm{VS}_{2}$ nanosheets for all-solid-state lithium batteries with enhanced electrochemical performances. ACS Appl. Mater. Interfaces 10 (2018) 10053-10063. https://doi.org/10.1021/acsami.7b18798.

[122] D.B. Putungan, S. Lin, J. Kuo, Metallic $\mathrm{VS}_{2}$ monolayer polytypes as potential sodium-ion battery anode via ab initio random structure searching. ACS Appl. Mater. Interfaces 8 (2016) 18754-18762. https://doi.org/10.1021/acsami.6bo3499.

[123] L. Zhang, L. Zuo, W. Fan, T. Liu, $\mathrm{NiCo}_{2} \mathrm{~S}_{4}$ nanosheets grown on $3 \mathrm{D}$ networks of nitrogen-doped graphene/carbon nanotubes: advanced anode materials for lithium-ion batteries. ChemElectroChem 3 (2016) 1384-1391. https://doi.org/10.1002/celc.201600183.

[124] R. Zou, Z. Zhang, M.F Yuen, M. Sun, J. Hu, C.-S. Lee, W. Zhang, Three-dimensional-networked $\mathrm{NiCo}_{2} \mathrm{~S}_{4}$ nanosheet array/carbon cloth anodes for high-performance lithium-ion batteries. NPG Asia Mater. 7 (2015) e 195. https://doi.org/10.1038/am.2015.63.

[125] J. Liu, J. Wang, Z. Ku, H. Wang, S. Chen, L. Zhang, J. Lin, Z.-X. Shen, Aqueous rechargeable alkaline $\mathrm{Co}_{\mathrm{x}} \mathrm{Ni}_{2-\mathrm{x}} \mathrm{S}_{2} / \mathrm{TiO}_{2}$ battery. ACS Nano 10 (2016) 1007-1016. https://doi.org/10.1021/acsnano.5bo6275.

[126] X. Liang, C. Hart, Q. Pang, A. Garsuch, T. Weiss, L.F. Nazar, A highly efficient polysulfide mediator for lithium-sulfur batteries. Nat. Commun. 6 (2015) 5682. https://doi.org/10.1038/ncomms6682.

[127] Q. Zhang, Y. Wang, Z.-W. She, Z. Fu, R. Zhang, Y. Cui, Understanding the anchoring effect of two-dimensional layered materials for lithium-sulfur batteries. Nano Lett. 15 (2015) 3780-3786. https://doi.org/10.1021/acs.nanolett.5boo367.

[128] G. Babu, N. Masurkar, H.A. Salem, L.M.R. Arava, Transition metal dichalcogenide atomic layers for lithium polysulfides electrocatalysis. J. Am. Chem. Soc. 139 (2017) 171-178. https://doi.org/10.1021/jacs.6bo8681.

[129] H. Li, C. Tsai, A.L. Koh, L. Cai, A.W. Contryman, A.H. Fragapane, J. Zhao, H. S. Han, H.C. Manoharan, F. Abild-Pedersen, J.K. Nørskov, X. Zheng, Activating and optimizing $\mathrm{MoS}_{2}$ basal planes for hydrogen evolution through the formation of strained sulphur vacancies. Nat. Mater. 15 (2016) 48-53. https://doi.org/10.1038/nmat4465.

[130] C. Zhu, D. Gao, J. Ding, D. Chao, J. Wang, TMD-based highly efficient electrocatalysts developed by combined computational and experimental approaches. Chem. Soc. Rev. 47 (2018) 43324356. https://doi.org/10.1039/C7CSoo705A.

[131] Y. Lai, W. Chen, Z. Zhang, Y. Gan, X. Yang, J. Li, Two-dimensional graphene-like $\mathrm{MoSe}_{2}$ Nanosheets anchored on hollow carbon nanofibers as a cathode catalyst for rechargeable $\mathrm{Li}-\mathrm{O}_{2}$ batteries. RSC Adv. 6 (2016) 19843-19847. https://doi.org/10.1039/c5ra27634a.

[132] M. Asadi, B. Kumar, C. Liu, P. Phillips, P. Yasaei, A. Behranginia, P. Zapol, R.F. Klie, L.A. Curtiss, A. Salehi-Khojin, Cathode based on molybdenum disulfide nanoflakes for lithium-oxygen batteries. ACS Nano 10 (2016) 2167-2175. https://doi.org/10.1021/acsnano.5bo6672.

[133] Z. Sadighi, J. Liu, L. Zhao, F. Ciucci, J.-K. Kim, Metallic MoS2 nanosheets: multifunctional electrocatalyst for the ORR, OER and $\mathrm{Li}-\mathrm{O}_{2}$ batteries. Nanoscale 10 (2018) 22549.

https://doi.org/10.1039/c8nro7106c.

[134] Q. Jiang, N. Kurra, C. Xia, H.N. Alshareef, Hybrid microsupercapacitors with vertically scaled $3 \mathrm{D}$ current collectors fabricated using a simple cut-and-transfer strategy. Adv. Energy Mater. 7 (2017) 1601257. https://doi.org/10.1002/aenm.201601257.

[135] N.A. Kyeremateng, T. Brousse, D. Pech, Microsupercapacitors as miniaturized energy-storage components for on-chip electronics. Nat. Nanotechnol. 12 (2017) 7-15. https://doi.org/10.1038/nnano.2016.196.

[136] M. Beidaghi, Y. Gogotsi, Capacitive energy storage in micro-scale devices: recent advances in design and fabrication of microsupercapacitors. Energy Environ. Sci. 7 (2014) 867-884. https://doi.org/10.1039/C3EE43526A.

[137] L. Zhang, M. Liao, L. Bao, X. Sun, H. Peng, The functionalization of miniature energy-storage devices. Small Mater. 1 (2017) 1700211. https://doi.org/10.1002/smtd.201700211.

[138] Y. Yan, P. Gu, S. Zheng, M. Zheng, H. Pang, H. Xue, Facile synthesis of an accordion-like Ni-MOF superstructure for high- performance flexible supercapacitors. J. Mater. Chem. A 4 (2016) 19078-19085. https://doi.org/10.1039/C6TAo8331E.

[139] A. Liu, H. Liu, Q. Li, H. Zhao, Two dimensional $\mathrm{MoS}_{2} / \mathrm{CNT}$ hybrid ink for paper-based capacitive energy storage. J. Mater. Sci-Mater. El. 28 (2017) 8452-8459. https://doi.org/10.1007/s10854-017-6564-8.

[140] N. Choudhary, C. Li, H.-S. Chung, J. Moore, J. Thomas, Y. Jung, High-performance one-body core/shell nanowire supercapacitor enabled by conformal growth of capacitive $2 \mathrm{D} \mathrm{WS}_{2}$ layers. ACS Nano 10 (2016) 10726-10735. https://doi.org/10.1021/acsnano.6bo6111.

[141] H. Wang, Z. Lu, S. Xu, D. Kong, J.J. Cha, G. Zheng, P.-C. Hsu, K. Yan, D. Bradshaw, F.B. Prinz, Y. Cui, Electrochemical tuning of vertically aligned $\mathrm{MoS}_{2}$ nanofilms and its application in improving hydrogen evolution reaction. Proc. Natl. Acad. Sci. U. S. A. 110 (2013) 19701-19706. https://doi.org/10.1073/pnas.1316792110.

[142] L. Zhao, C. Hong, L. Lin, H. Wu, Y. Su, X. Zhang, A. Liu, Controllable nanoscale engineering of vertically aligned $\mathrm{MoS}_{2}$ ultrathin nanosheets by nitrogen doping of $3 \mathrm{D}$ graphene hydrogel for improved electrocatalytic hydrogen evolution. Carbon 16 (2017) 223231. https://doi.org/10.1016/j.carbon.2017.02.010.

[143] A. Liu, L. Zhao, J. Zhang, L. Lin, H. Wu, Solvent-assisted oxygen incorporation of vertically aligned $\mathrm{MoS}_{2}$ ultrathin nanosheets decorated on reduced graphene oxide for improved electrocatalytic hydrogen evolution. ACS Appl. Mater. Interfaces 8 (2016) 25210-25218. https://doi.org/10.1021/acsami.6bo6o31.

[144] H. Wang, D. Kong, P. Johanes, J.J. Cha, G. Zheng, K. Yan, N. Niu, Y. Cui, $\mathrm{MoSe}_{2}$ and $\mathrm{WSe}_{2}$ nanofilms with vertically aligned molecular layers on curved and rough surfaces. Nano. Lett. 13 (2013) 3426-3433. https://doi.org/10.1021/nl401944f.

[145] D. Kong, H. Wang, J.J. Cha, M. Pasta, K.J. Koski, J. Yao, Y. Cui, Synthesis of $\mathrm{MoS}_{2}$ and $\mathrm{MoSe}_{2}$ films with vertically aligned layers. Nano Lett. 13 (2013) 1341-1347. https://doi.org/10.1021/nl400258t.

[146] Y. Yang, H. Fei, G. Ruan, C. Xiang, J.M. Tour, Edge-oriented $\mathrm{MoS}_{2}$ nanoporous films as flexible electrodes for hydrogen evolution reactions and supercapacitor devices. Adv. Mater. 26 (2014) 81638168. https://doi.org/10.1002/adma.201402847.

[147] L. David, R. Bhandavat, G. Singh, $\mathrm{MoS}_{2}$ /graphene composite paper for sodium-ion battery electrodes. ACS Nano 8 (2014) 1759177o. https://doi.org/10.1021/nn406156b.

[148] Y. Liu, X. He, D. Hanlon, A. Harvey, J.N. Coleman, Y. Li, Liquid phase exfoliated $\mathrm{MoS}_{2}$ nanosheets percolated with carbon nanotubes for high volumetric/areal capacity sodium-ion batteries. ACS Nano 10 (2016) 8821-8828. https://doi.org/10.1021/acsnano.6bo4577.

[149] Y. Gogotsi, P. Simon, True performance metrics in electrochemical energy storage. Science 334 (2011) 917-918. https://doi.org/10.1126/science.1213003.

[150] J. Luo, X. Tao, J. Zhang, Y. Xia, H. Huang, L. Zhang, Y. Gan, C. Liang, W. Zhang, $\mathrm{Sn}^{4+}$ Ion decorated highly conductive $\mathrm{Ti}_{3} \mathrm{C}_{2}$ MXene: Promising lithium-ion anodes with enhanced volumetric capacity and cyclic performance. ACS Nano 10 (2016) 2491-2499. https://doi.org/10.1021/acsnano.5bo7333.

[151] T.M. Higgins, S.-H. Park, P.J. King, C. Zhang, N. McEvoy, N.C. Berner, D. Daly, A. Shmeliov, U. Khan, G. Duesberg, V. Nicllosi, J.N. Coleman, A commercial conducting polymer as both binder and conductive additive for silicon nanoparticle-based lithiumion battery negative electrodes. ACS Nano 10 (2016) 3702-3713. https://doi.org/10.1021/acsnano.6boo218.

[152] Y. Liu, Y. Yang, X. Wang, Y. Dong, Y. Tang, Z. Yu, Z. Zhao, J. Qiu, Flexible paper-like free-standing electrodes by anchoring ultrafine $\mathrm{SnS}_{2}$ nanocrystals on graphene nanoribbons for high-performance sodium ion batteries. ACS Appl. Mater. Interfaces 9 (2017) 1548415491. https://doi.org/10.1021/acsami.7bo2394.

[153] K.S. Novoselov, A.K. Geim, S.V. Morozov, D. Jiang, Y. Zhang, S.V. Dubonos, I.V. Grigorieva, A.A. Firsov, Electric field effect in atomically thin carbon films. Science 306 (2004) 666-669. https://doi.org/10.1126/science.1102896.

[154] Y. Zhang, J. Shi, G. Han, M. Li, Q. Ji, D. Ma, Y. Zhang, C. Li, X. Lang, Y. Zhang, Z. Liu, Chemical vapor deposition of monolayer $\mathrm{WS}_{2}$ nanosheets on Au foils toward direct application in hydrogen evolution. Nano Res. 8 (2015) 2881-289o. https://doi.org/10.1007/s12274-015-0793-z. 
[155] G. Ye, Y. Gong, J. Lin, B. Li, Y. He, S.T. Pantelides, W. Zhou, R. Vajtai, P.M. Ajayan, Defects engineered monolayer $\mathrm{MoS}_{2}$ for improved hydrogen evolution reaction. Nano Lett. 2016, 16, 1097-1103. 10.1021/acs.nanolett.5bo4331.

[156] Y. Lei, S. Pakhira, K. Fujisawa, X. Wang, O.O. Iyiola, N.P. López, A.L. Elías, L.P. Rajukumar, C. Zhou, B. Kabius, N. Alem, M. Endo, R. Lv, J.L. Mendoza-Cortes, M. Terrones, Low-temperature synthesis of heterostructures of transition metal dichalcogenide alloys $\left(\mathrm{W}_{\mathrm{x}} \mathrm{Mo}_{1-\mathrm{x}} \mathrm{S}_{2}\right)$ and graphene with superior catalytic performance for hydrogen evolution. ACS Nano 11 (2017) 5103-5112. https://doi.org/10.1021/acsnano.7bo2o6o.

[157] A.K. Geim, I.V. Grigorieva, Van der Waals heterostructures. Nature 399 (2013) 419-425. https://doi.org/10.1038/nature12385.

[158] K.S. Novoselov, A. Mishchenko, A. Carvalho, A.H. Castro Neto, 2D materials and van der Waals heterostructures. Science 353 (2016) aac9439. https://doi.org/10.1126/science.aac9439.

[159] E. Pomerantseva, Y. Gogotsi, Two-dimensional heterostructures for energy storage. Nat. Energy 2 (2017) 17089. https://doi.org/10.1038/nenergy.2017.89.

[16o] Z. Zhao, F. Qin, S. Kasiraju, L. Xie, M.K. Alam, S. Chen, D. Wang, Z. Ren, Z. Wang, L.C. Grabow, J. Bao, Vertically aligned $\mathrm{MoS}_{2} / \mathrm{Mo}_{2} \mathrm{C}$ hybrid nanosheets grown on carbon paper for efficient electrocatalytic hydrogen evolution. ACS Catal. 7 (2017) 7312-7318. https://doi.org/10.1021/acscatal.7bo2885.

[161] E.G. da Silveria Firmiano, A.C. Rabelo, C.J. Dalmaschio, A.N. Pinheiro, E.C. Pereria, W.H. Schreiner, E.R. Leite, Supercapacitor electrodes obtained by directly bonding $2 \mathrm{D} \mathrm{MoS} 2$ on reduced graphene oxide. Adv. Energy Mater. 4 (2014) 1301380. https://doi.org/10.1002/aenm.201301380.

[162] J.N. Coleman, M. Lotya, A. O’Neill, S.D. Bergin, P.J. King, U. Khan, K. Young, A. Gaucher, S. De, R.J. Smith, J.V. Shvets, S.K. Arora1, G. Stanton, H.-Y. Kim, K. Lee, G.T. Kim, G,S. Duesberg, T. Hallam, J.J. Boland, J. Wang, J.F. Donegan, J.C. Grunlan, G. Moriarty, A. Shmeliov, R.J. Nicholls, J.M. Perkins, E.M. Grieveson, K. Theuwissen, D.W. McComb, P.D. Nellist, V. Nicolosi, Two-dimensional nanosheets produced by liquid exfoliation of layered materials. Science 331 (2011) 568-571. https://doi.org/10.1126/science.1194975.

[163] D. Voiry, H. Yamaguchi, J. Li, R. Silva, D.C.B. Alves, T. Fujita, M. Chen, T. Asefa, V.B. Shenoy, G. Eda, M. Chhowalla, Enhanced catalytic activity in strained chemically exfoliated WS2 nanosheets for hydrogen evolution. Nat. Mater. 12 (2013) 850-855. https://doi.org/10.1038/nmat370o.

[164] H.S.S. Ramakrishna Matte, A. Gomathi, A.K. Manna, D.J. Late, R. Datta, S.K. Pati, C.N. R. Rao, $\mathrm{MoS}_{2}$ and $\mathrm{WS}_{2}$ analogues of graphene. Angew. Chem. Int. Ed. 2010, 49, 4059-4062. https://doi.org/10.1002/anie.201000009.

[165] J. Jiang, S. Zhang, S.A. Kulinich, X. Song, J. Zhu, X. Wang, H. Zeng, Optimizing hybridization of $1 \mathrm{~T}$ and $2 \mathrm{H}$ phases in $\mathrm{MoS}_{2}$ monolayers to improve capacitances of supercapacitors. Mater. Res. Lett. 3 (2015) 177-183. https://doi.org/10.108o/21663831.2015.1057654.

[166] S. Ratha, C.S. Rout, Supercapacitor electrodes based on layered tungsten disulfide-reduced graphene oxide hybrids synthesized by a facile hydrothermal method. ACS Appl. Mater. Interfaces 5 (2013) 11427-11433. https://doi.org/10.1021/am403663f.

[167] A. Khalil, Q. Liu, Q. He, T. Xiang, D. Liu, C. Wang, Q. Fang, L. Song, Metallic $1 \mathrm{~T}-\mathrm{WS}_{2}$ nanoribbons as highly conductive electrodes for supercapacitors. RSC Adv. 6 (2016) 48788-48791. https://doi.org/10.1039/c6rao8975e.

[168] T.-W. Lin, T. Sadhasivam, A.-Y. Wang, T.-Y. Chen, J.-Y. Lin, L.-D. Shao, Ternary composite nanosheets with $\mathrm{MoS}_{2} / \mathrm{WS}_{2} /$ graphene heterostructures as high-performance cathode materials for supercapacitors. ChemElectroChem 5 (2018) 1024-1031. https://doi.org/10.1002/celc.201800043.

[169] S.K. Balasingam, J.S. Lee, Y. Jun, Few-layered $\mathrm{MoSe}_{2}$ nanosheets as an advanced electrode material for supercapacitors. Dalton Trans. 44 (2015) 15491-15498. https://doi.org/10.1039/C5DTo1985K.

[170] H. Peng, J. Zhou, K. Sun, G. Ma, Z. Zhang, E. Feng, Z. Lei, Highperformance asymmetric supercapacitor designed with a novel $\mathrm{NiSe} @ \mathrm{MoSe}_{2}$ nanosheet array and nitrogen-doped carbon nanosheet. ACS Sustain. Chem. Eng. 5 (2017) 5951-5963. https://doi.org/10.1021/acssuschemeng.7boo729.
[171] Q. Ji, C. Li, J. Wang, J. Niu, Y. Gong, Z. Zhang, Q. Fang, Y. Zhang, J. Shi, L. Liao, X. Wu, L. Gu, Z. Liu, Y. Zhang, Metallic vanadium disulfide nanosheets as a platform material for multifunctional electrode applications. Nano Lett. 17 (2017) 4908-4916. https://doi.org/10.1021/acs.nanolett.7bo1914.

[172] A. Chang, C. Zhang, Y. Yu, Y. Yu, B. Zhang, Plasma-assisted synthesis of $\mathrm{NiSe}_{2}$ ultrathin porous nanosheets with selenium vacancies for supercapacitor. ACS App. Mater. Interfaces 10 (2018) 41861-41865. https://doi.org/10.1021/acsami.8b16o72.

[173] J. Wu, J. Peng, Z. Yu, Y. Zhou, Y. Guo, Z. Li, Y. Lin, K. Ruan, C. Wu, Y. Xie, Acid-assisted exfoliation toward metallic sub-nanopore $\mathrm{TaS}_{2}$ monolayer with high volumetric capacitance. J. Am. Chem. Soc. 140 (2018) 493-498. https://doi.org/10.1021/jacs.7b11915.

[174] Y. Cao, R. Jalili, Y Ge, C. Wang, T. Zheng, K. Shu, G.G. Wallace, Self-assembly of flexible free-standing $3 \mathrm{D}$ porous $\mathrm{MoS}_{2}$-reduced graphene oxide structure for high-performance lithium-ion batteries. Adv. Funct. Mater. 27 (2017) 1700234.

https://doi.org/10.1002/adfm.201700234.

[175] P. Li, J. Y. Jeong, B. Jin, K. Zhang, J. H. Park, Vertically oriented MoS2 with spatially controlled geometry on nitrogenous graphene sheets for high-performance sodium-ion batteries. Adv. Energy Mater. 8 (2018) 1703300. https://doi.org/10.1002/aenm.201703300.

[176] H. Li, L. Yang, X. Jiang, G. Li, T. Zhang, Q. Yao, G.W Zheng, J.Y. Lee, Energy Environ. Sci. 10 (2017) 1476-1486. https://doi.org/10.1039/c7eeo1047h.

[177] J. Ren, Z. Wang, F. Yang, R.-P. Ren, Y.-K. Lv, Freestanding 3 D single-wall carbon nanotubes/ $\mathrm{WS}_{2}$ nanosheets foams as ultralong-life anodes for rechargeable lithium ion batteries. 267 (2018) 133-140. https://doi.org/10.1016/j.electacta.2018.01.167.

[178] J. Zhou, J. Qin, L. Guo, N. Zhao, C. Shi, E. Liu, F. He, L. Ma, J. Lu, C. He, Scalable synthesis of high-quality transition metal dichalcogenide nanosheets and their application as sodium-ion battery anodes. J. Mater. Chem. A 4 (2016) 17370-17380. https://doi.org/10.1039/c6tao7425a.

[179] T. Lei, W. Chen, J. Huang, C. Yan, H. Sun, C. Wang, W. Zhang, Y. $\mathrm{Li}$, J. Xiong, Multi-functional layered WS2 nanosheets for enhancing the performance of lithium-sulfur batteries. Adv. Energy Mater. 7 (2017) 1601843. https://doi.org/10.1002/aenm.201601843.

[18o] R. Sun, Q. Wei, J. Sheng, C. Shi, Q. An, S. Liu, L. Mai, Novel layerby-layer stacked VS2 nanosheets with intercalation pseudocapacitance for high-rate sodium ion charge storage. Nano Energy 35 (2017) 396-404. http://dx.doi.org/10.1016/j.nanoen.2017.03.036.

[181] X. Zhu, W. Zhao, Y. Song, Q. Li, F. Ding, J. Sun, L. Zhang, Z. Liu, In situ assembly of $2 \mathrm{D}$ conductive vanadium disulfide with graphene as a high-sulfur-loading host for lithium-sulfur batteries. Adv. Energy Mater8 (2018) 1800201.

https://doi.org/10.1002/aenm.201800201.

[182] Z. Luo, J. Zhou, L. Wang, G. Fang, A. Pan, S. Liang, Twodimensional hybrid nanosheets of few layered $\mathrm{MoSe}_{2}$ on reduced graphene oxide as anodes for long-cycle-life lithium-ion batteries. J. Mater. Chem. A 4 (2016) 15302-15308. https://doi.org/10.1039/c6tao439oa.

[183] J. Choi, J. Jin, Il G. Jung, J.M. Kim, H. J. Kim, S.U. Son, $\mathrm{SnSe}_{2}$ nanoplate-graphene composites as anode materials for lithium ion batteries. Chem. Commun. 47 (2011) 5241-5243. https://doi.org/10.1039/c1cc10317b.

[184] W. Sun, X. Rui, D. Yang, Z. Sun, B. Li, W. Zhang, Y. Zong, S. Madhavi, S. Dou, Q. Yan, Two-dimensional tin disulfide banosheets for enhanced sodium storage. ACS Nano 9 (2015) 11371-11381. https://doi.org/10.1021/acsnano.5bo5229.

[185] J. Zhang, C. Du, J. Zhao, H. Ren, Q. Liang, Y. Zheng, S. Madhavi, X. Wang, J. Zhu, Q. Yan, $\mathrm{CoSe}_{2}$-decorated $\mathrm{NbSe}_{2}$ nanosheets fabricated via cation exchange for Li storage. ACS Appl. Mater. Inferfaces 10 (2018) 37773-37778. https://doi.org/10.1021/acsami.8b15457.

[186] J. Xie, H. Zhang, S. Li, R. Wang, X. Sun, M. Zhou, J. Zhou, X. Lou, Y. Xie, Defect-rich $\mathrm{MoS}_{2}$ ultrathin nanosheets with additional active edge sites for enhanced electrocatalytic hydrogen evolution. Adv. Mater. 25 (2013) 5807-5813. https://doi.org/10.1002/adma.201302685. 
[187] Y. Qu, H. Pan, C. T. Kwok, Z. Wang, Effect of doping on hydrogen evolution reaction of vanadium disulfide monolayer. Nanoscale Res. Lett. 10 (2015) 480. https://doi.org/10.1186/s11671-015-1182-y.

[188] G. Liu, A.W. Robertson, M.M. Li, W.C.H. Kuo, M.T. Darby, M.H. Muhieddine, Y. Lin, K. Suenage, M. Stamatakis, J.H. Warner, S.C.E. Tsang, $\mathrm{MoS}_{2}$ monolayer catalyst doped with isolated Co atoms for the hydrodeoxygenation reaction. Nat. Chem. 9 (2017) 810-816. https://doi.org/10.1038/nchem.2740.

[189] X. Shu, M. Fields, J. Park, J.M. McEnaney, H. Yan, Y. Zhang, C. Tsai, T. F. Jaramillo, R. Sinclair, J. K. Nørskov, X. Zheng, Rapid flame doping of Co to $\mathrm{WS}_{2}$ for efficient hydrogen evolution. Energy Environ. Sci. 11 (2018) 2270-2277. https://doi.org/10.1039/C8EEo111G.

[190] X. Zheng, X. Xiong, J. Yang, D. Chen, R. Jian, L. Lin, A strong and compressible three dimensional graphene/polyurushiol composite for efficient water cleanup. Chem. Eng. J. 333 (2018) 153-161. https://doi.org/10.1016/j.cej.2017.09.146.

[191] J. Liu, J. Wang, C. Xu, H. Jiang, C. Li, L. Zhang, J. Lin, Z.-X. Shen, Advanced energy storage devices: basic principles, analytical methods, and rational materials design. Adv. Sci. 5 (2018) 1700322. https://doi.org/10.1002/advs.201700322.

[192] D. Voiry, R. Fullon, J. Yang, C. de Carvalho Castro e Silva, R. Kappera, I. Bozkurt, D. Kaplan, M.J. Lagos, P.E. Batson, G. Gupta, A.D. Mohite, L. Dong, D. Er, V.B. Shenoy, T. Asefa, M. Chhowalla, The role of electronic coupling between substrate and ${ }_{2} \mathrm{D} \mathrm{MoS}$ nanosheets in electrocatalytic production of hydrogen. Nat. Mater. 15 (2016) 1003-1009. https://doi.org/10.1038/nmat466o. 